\title{
DISRUPTING WHITENESS WITHIN ACADEMIA: EXAMINING THE EXPERIENCES AND UNDERSTANDING OF WHITENESS AMONG WHITE STUDENTS ATTENDING RYERSON UNIVERSITY
}

by

Danuta Gawron, Bachelor of Social Work (BSW), Ryerson University, 2019

\author{
An MRP \\ presented to Ryerson University \\ in partial fulfillment of the \\ requirements for the degree of \\ Master of Social Work \\ in the program of \\ Social Work
}

Toronto, Ontario, Canada, 2020

(C) Danuta Gawron, 2020 


\section{AUTHOR'S DECLARATION}

I hereby declare that I am the sole author of this MRP. This is a true copy of the MRP, including any required final revisions.

I authorize Ryerson University to lend this MRP to other institutions or individuals for the purpose of scholarly research

I further authorize Ryerson University to reproduce this MRP by photocopying or by other means, in total or in part, at the request of other institutions or individuals for the purpose of scholarly research.

I understand that my MRP may be made electronically available to the public. 


\begin{abstract}
DISRUPTING WHITENESS WITHIN ACADEMIA: EXAMINING THE EXPERIENCES AND UNDERSTANDING OF WHITENESS AMONG WHITE STUDENTS ATTENDING RYERSON UNIVERSITY
\end{abstract}

Master of Social Work, 2020

Danuta Gawron

Social Work, Ryerson University

This narrative qualitative research study explored the experiences and understanding of whiteness from three full-time white students at Ryerson University (RU). The theoretical framework draws from Critical Whiteness Studies (CWS) and Critical Whiteness Pedagogy (CWP). Based on existing literature on whiteness, this study utilized semi-structured telephone interviews with the three participants. The participants were randomly selected through recruitment posting and flyers on social media outlets such as Facebook. Data analysis included a thematic and structure of the narratives of the participants. The findings provided insight into how these white students at RU define whiteness and how they understand whiteness demonstrated in academia and, lastly, whether they have perpetrated or fought against whiteness within their academic institution. The results indicate that whiteness is not easily defined, and academia is incorporating diverse perspectives. This paper concludes with implications and discussion on future social work, followed by the conclusion.

Key words: Academia, Critical Whiteness Studies, Critical Whiteness Pedagogy, colonialization, gender, whiteness, white students, 


\section{ACKNOWLEDGEMENTS}

I would like to take this opportunity to thank several individuals who have helped me on my journey. Firstly, I would like to thank my supervisor, Gordon Pon for his guidance through each stage of the process. Secondly, I like to thank Ryerson University and all the amazing professors who taught me so much and ignited my passion in social work. Thirdly, I like to thank all my 2019-2020 MSW cohort. Despite all that is occurring due to covid-19 we made it, and I am proud of us! Lastly, I like to thank my family who supported and believed in me throughout my educational experience. 


\section{DEDICATION}

This is for my daughters T and L, everything I do is for the betterment of your lives. My life has no purpose without you girls. You have made me into the woman that I am now. My heart and soul fills with joy and happiness because I have you and I am grateful that you have chosen me as your mother to support you on your journey through life.

This is also to my mother who supported me throughout my life and never doubted me. You have made this possible for me. THANK YOU! 


\section{TABLE OF CONTENTS}

Page

Chapter 1: INTRODUCTION 1

Chapter 2: LITERATURE REVIEW 5

$\begin{array}{ll}\text { Chapter 3: THEORETICAL FRAMEWORK } & 19\end{array}$

$\begin{array}{ll}\text { Chapter 4: METHODOLOGY } & 24\end{array}$

$\begin{array}{ll}\text { Chapter 5: FINDINGS } & 30\end{array}$

$\begin{array}{ll}\text { Chapter 6: ANALYSIS } & 46\end{array}$

$\begin{array}{ll}\text { Chapter 7: IMPLICATIONS } & 56\end{array}$

$\begin{array}{lr}\text { Chapter 8: CONCLUSION } & 60\end{array}$

$\begin{array}{ll}\text { Appendices } & 62\end{array}$

$\begin{array}{ll}\text { Endnotes } & 73\end{array}$

$\begin{array}{ll}\text { Reference List } & 74\end{array}$ 


\section{LIST OF APPENDICES}

Page

Appendix A - Recruitment Flyer $\quad 62$

Appendix B - Facebook Recruitment Notice/Posting Script 63

Appendix C - Interview Guide 64

Appendix D - Consent Form 66

Appendix E - Ryerson University Research Ethic Board Certificate 71 


\section{CHAPTER 1. INTRODUCTION}

"If you don't think representation is important, then you're probably very well represented."

\section{Mariko Tamaki}

-Ro, 2019

After six years in post-secondary education in the social work program, I have had to unlearn and re-learn what I have been conditioned to know about race, power, oppression, colonialism, and how I see myself in connection to these implications. I have sat too comfortably in my own whiteness and been oblivious to the experiences of racialized individuals and communities. However, throughout my academic learning, I have begun the process of critical reflexivity, where I examine my footprints on this land and every interaction I have. Through this reflexivity, I begin the journey of decolonizing the spaces that I occupy.

\section{Who Am I?}

I begin by situating myself within this research. I am a white settler to this land. As Tuck and Yang (2012) explain, settlers come intending to make a new home on the land (p.5). My family was not forced to leave. We did not apply as refugees but simply as permanent residents with the promise to contribute to the economic growth of Canada. My knowledge and ways of knowing are rooted within the Canadian context, which is aligned with Western and European ideologies that uplift whiteness. Growing up, I was very sheltered and privileged. I never faced oppression that created fear, discrimination, or isolation, because of one's sexuality, race, religion, and ability. I walked through life oblivious of my whiteness and the effects of colonization and its racist ideologies attached to it. 


\section{Purpose of Paper}

Discussions of oppression, whiteness, privilege, colonization, and anti-black racism have been a focal point of my learning. I know as a white female settler that I have certain privileges that enable me to maneuver in society which continues to discriminate and marginalize individuals who do not represent the status quo. I am grateful for the knowledge about whiteness that I have gained from my program. However, with my years of experience in post-secondary institutions, one cannot help but be aware of the disproportionately low number of non-white students accepted into various programs at post-secondary institutions compared to white students. I began questioning pedagogical practices in post-secondary institutions and whether discussions on whiteness, oppression, power, and privilege are ingrained in programs other than Social Work. Moreover, I have been interested in knowing whether white students are aware of whiteness and do they acknowledge their white privilege in academia?

My commitment to decolonizing has led me to explore and examine whiteness among my fellow white students at Ryerson University (RU). The purpose of this research is to capture the narratives of white RU students and explore their experiences and understanding of whiteness and how they have either perpetrated or fought against systematic oppression, racism and marginalization within their academic institution. This paper is divided into various chapters. In the first chapter, I will begin with a brief description of RU. Then in chapter two, I will analyze specific literatures that pertain to whiteness in academia and discuss the limitations of this literature. In chapter three, I will describe the theoretical frameworks of critical whiteness studies and critical whiteness pedagogy that inform this research study, followed by chapter four, where I will describe the methodology of narrative approach which was used in this research study. Using a narrative approach, I interviewed three white students who were attending RU. The last 
three chapters will focus on the findings of the research, the analysis, the implications, and conclusion. The results indicate that whiteness is not easily defined, and academia is incorporating diverse perspectives. The MRP concludes by emphasizing that it is time for white people to stop and accept their white privileges and to challenge them. It is time that our leaders, our educational systems, criminal justice systems, health care systems, policy makers and anyone in power begin to reflect the faces of all Canadians and not just the dominant white ones.

\section{Ryerson University}

Ryerson University (RU) is a highly well-known institution located in downtown Toronto. Toronto is known as the hub of multiculturalism in Canada. According to the 2016 Canadian Census, Toronto has over $1,385,850$ people who identity as a visible minority (Statistics Canada, 2017). Under the Employment Equity Act, visible minorities are defined as "persons, other than Aboriginal peoples, who are non-Caucasian in race or non-white in colour" (Statistics Canada, 2017). The abundance of diversity in Toronto should be reflected by the university's faculty and students; however, student race-based data at RU is not collected by the institution. Instead, RU collects non-race-based data regarding enrolment.

RU was founded in 1948 (Doucet, 2007, par.1). Students globally come to RU to enhance their knowledge and education in their field of choice. According to their website RU is the "most applied-to university in Ontario" with over 45,000 students and 100+ undergraduate and graduate programs (Ryerson University, n.d.). The university was named after Egerton Ryerson who is known as the "architect of Ontario’s educational system” (Doucet, 2007, par.1). He also played a significant role in establishing "separate, parallel systems of schooling, including institutionalized schooling for disabled students, reforming-focused schools for lower- and working-class students, segregated schools for Black students and residential schools for 
Indigenous students" (Knight, 2019, p.91). Despite Egerton Ryerson's controversial role in shaping the ideologies and norms of the Canadian educational system, RU continues to grow and evolve in its mission to: "provide leadership in career-focused education and to fulfill contemporary societal needs" (Doucet, 2007, par.9). 


\section{CHAPTER 2. LITERATURE REVIEW}

\section{Introduction}

A literature review was conducted on qualitative research studies on this topic concerning white students and whiteness. Among the themes identified in the literature, whiteness became the reoccurring theme. Utilizing whiteness as the umbrella topic, this chapter will first and foremost explore the concept of whiteness as it appears in the literature, investigate its roots in colonialism, and the relation in a Canadian context. The second theme will discuss whiteness in academia. Lastly, the third theme will explore pedagogical practices.

The literature came from various disciplines and affiliation of well-known universities across Canada, the United States, the United Kingdom, and Norway. However, the department of sociology was a significant source of knowledge amongst the literature. These articles focused their research on the developmental and structural function of human society. Other knowledge grew out of cultural studies, occupational therapy, educational studies, diversity, equity and inclusion studies and lastly, psychology.

To conduct my literature search I used Ryerson University Library databases including: ProQuest Research Library, Social Services Abstracts, Social Work Abstracts, Google Scholar and PsycInfo. The search terms used were: whiteness in academia, white students' perception of whiteness, white faculty, and white pedagogy. Taken into consideration were the years the articles were published, and if there was Canadian content.

\section{Whiteness}

Discussion of whiteness was a prominent theme amongst the literature. The research elaborated ways whiteness has been instrumental in socially constructing how we interact with one another. The literature discussed how White people operate from a culturally inherited White 
racial frame of White superiority through which they make sense of the world (Yeung, Spanierman \& Landrum-Brown, 2013, p.17). Furthermore, the literature articulated ways in which whiteness has evolved into mainstream society and its responsibility for systematic oppression. However, to fully grasp the meaning of whiteness, I turn to Ruth Frankenberg's (1993) definition. The author states:

whiteness has a set of linked dimensions...first, whiteness is a location of structural advantage, of race privilege...second, it is a "standpoint", a place from which white people look at ourselves, at others, and at society...third, "whiteness" refers to a set of cultural practices that are usually unmarked and unnamed. (p.1)

Whiteness is not equal to white people (Matias \& Newlove, 2017, p. 317). It is a "socially constructed norm that centers white privilege at the cost of other cultures" (de Freitas \& McAuley, 2008, p.431). Moreover, it is the "hegemonic racial power that privileges white groups while subordinating racialized 'others'" (Hikido \& Murray, 2016, p.391). Charbeneau (2015) proclaims whiteness is a social construction, an individual experience, with a set of objective rules and relationships that is established and guided by institutions and individuals (p.655). It can be executed and preserved by racialized groups; however, by a different process than Whites (Matias \& Newlove, 2017, p.317). Therefore, whiteness comprises the "ideologies, emotions, rhetoric, symbolism and speech that, upon its expression, is set to dominate or control a populace without even actively acknowledging such domination" (Matias \& Newlove, 2017, p.317). Thus, whiteness is ongoing and unfinished, and positions white bodies in a specific direction that affects the way they occupy various spaces (Duhaney, 2010, p.98). Whiteness "seems" natural, and in doing so becomes almost invisible until challenged" (Matias \& Newlove, 2017, p.318). Matias and Newlove (2017) assert that although an individual may not employ whiteness 
intentionally, they argue that whiteness is not about the intent as much as it is about the impact (p.317).

\section{White Supremacy}

Whiteness has many elements that are adopted and maintained, such as white supremacy (Applebaum, 2016; Matias \& Newlove, 2017). Applebaum (2016) defines white supremacy as the "everyday practices and policies that are made invisible through normalization and thus are often taken for granted as just what is" (p.4). Similarly, Matias and Newlove (2017) assert that white supremacy goes further than one's prejudice belief to include systematic institutions that benefit Whites over marginalized groups (p.317). For Whites, white supremacy is manifested through "white privilege, racial entitlement, a sense of superiority, white racialization, white emotionalities, nativism, xenophobia, and naturalization, each with an entire subfield" (Matias, \& Newlove, 2017, p.318). White supremacy for marginalized groups is manifested through forms of oppression, discrimination, and racism that are reproduced in policies and procedures that only privilege white bodies (Applebaum, 2016, p.4)

\section{Roots to Colonialism}

Whiteness is historical, political, and social. It has deep roots in colonialism and European history (Baffoe, Asimeng-Boahene \& Ogbuagu, 2014, p.14). In the Canadian context, colonialism took the form of settler-colonialism in which settler societies did not come only to extract labour and resources but to build and settle on the land (Marom, 2019, p.321). As a result, settler-colonialism gave birth to various policies and practices that have led to the oppression and marginalization of Indigenous peoples during post-contact (Marom, 2019, p.322). These policies and practices are evident throughout Canadian history and are created and maintained through 
immigration and migration laws to create a "white" North America (Baffoe et al., 2014;

Bohonos, 2019; Nayak, 2007).

However, Nayak (2007) and Ambrosio (2014) argue that the effects of whiteness has been, and still is, detrimental to white bodies. They explain that whiteness has expanded to encompass hierarchy amongst white individuals in relation to their social class and academic achievements (Ambrosia, 2014, p.1381). The expansion of whiteness emerged during the American labour revolution (Nayak, 2007, p.739). New immigrants from Southern and Eastern Europe, Catholics, Jews, the Irish and rural peasants were seldom deemed 'white" (Nayak, 2007, p.739). However, as the workforce became in need of labour, white groups who during that time were discriminated against on the grounds of religion or country of origin gained employment (Nayak, 2007, p.739). Although they were never considered 'white,' they acquired the discourses of what it means to be a 'white citizen' in America by being 'servants to the capital' (Nayak, 2007, p.739). Nayak (2007) asserts that whiteness became an exchange value in the labour market, a race "currency" that operated as the driving force within the American labour revolution and today's society (p.739).

Furthermore, Nayak (2007) explores the concept of whiteness functioning as a "cultural category" in which to be respected one needs to embody "white qualities" such as fairness, skills, and ability to hold a job that reflects the cultural achievement of whiteness (Nayak, 2007, p.741). As a result, Bohonos (2019) proclaims that European whites were successful in earning their acceptance by dominant Whites by embodying themselves with 'white qualities' and discourses, as well, by positioning themselves against Blacks (p.320). Similarly, Dryer (1997) clarifies that white people were categorized not because of the colour of their skin, but as a social category based on what it meant to be white; not being a slave (p.50). Therefore, 'poor' white people were 
socially advantaged because of their complexion which provided access to privilege, power, opportunity, and wealth (Dryer, 1997, p.52).

However, Ambrosio (2014) and Nayak (2007) argue that the current discrepancies between class and income goes far beyond the dichotomy of white and black individuals. Since the 1960s the income achievement gap between individuals from high- and low-income has grown 40\%, surpassing the gap between the black-white achievement gap (Ambrosio, 2014, p.1381). Moreover, recent studies have found the $57 \%$ of white individuals from a lower class remain at the bottom and $71 \%$ remain stuck in the middle (Ambrosio, 2014, p.1381). Although Black individuals continue to be socially and economically worse off than whites, studies have shown that whites who were raised from a low-income class remain wedged there as adults (Ambrosio, 2014, p.1381). Equally, Nayak (2007) proclaims that modern-day ideologies of whiteness have expanded past material privilege (p.741). Instead, Nayak (2007) argues, whiteness has moved towards a "cultural attitude" in which there can only be two forms of white people, the 'high' class and the 'low' class (p.741). Consequently, "poor" white communities who culturally and historically have been casted out for not embodying white characteristics have been negatively targeted and portrayed in numerous media outlets, advertisement and film for not reflecting the cultural achievements and norms of whiteness (Nayak, 2007, p.741).

\section{Whiteness and Gender}

Torres and Pace (2005) proclaim that "whiteness has a gender" (p.130). Historically, state authorities "emerged as male power, and male power in its cardinal expression was white" (Torres \& Pace, 2005, p.133). The expansion of Empires to the New World not only resulted in the genocide of Indigenous Peoples, the enslavement of African people and the extraction of resources, but also came with them Eurocentric ideologies of patriarchy. Both gender and race 
are social constructions, however, these roles have long been implicated together throughout historical, geographical, and cultural norms (Torres \& Pace, 2005, p.131). Whiteness possesses "certain superior characteristics that on closer inspection turned out to be as gendered as they were racial" (Torres \& Pace, 2005, p.130). Moreover, Hatt (2016) declares that any discussion on whiteness conjures up in our mind an over-whelming framed image of a white, wealthy man (p.1141). This is due to the fact that we have been cultural, historically and politically embedded with these images and symbols of whiteness that represent patriarchy and masculinity (Hatt, 2016, p.1141). So much that these ideologies have reinforced attitudes that position (white) women are subordinate to white men (Torres \& Pace, 2005, p.131).

As a result, feminism arose because of the existing gender relations and discrimination against women. However, feminism does not go unnoticed without critique. Many scholars argue that the core foundation of feminism, also known as white feminism, essentially conceals and ignores the racial discrepancy of female subordination and upholds the power and privilege that is associated with whiteness (Arndt, 2005; Frankenberg, 1999). From the birth of the first wave, the feminist fight only addressed the struggles and challenges of white women. Arndt (2005) argues that whiteness is the unspoken norm amongst white feminism where feminism has always been about claiming rights for white women (p.158). Frankenberg (1999) declares that white women are lacking the critical awareness in how their position in society is constructed in relation to racialized women and men (p.9). Though not to defend white women, Frankenberg (1999) argues that white women are racially privileged because of whiteness, and therefore, white women are not structurally positioned to see the effects of racism (p.9). 


\section{Whiteness in Academia}

Another critical theme found in the literature emphasized educational institutions' involvement in silencing marginalized voices. The foundation of tertiary education has functioned from a historically white space legitimatizing only certain types of knowledge through research, journal articles, and curriculum (Mohamed \& Beagan, 2019; Murray \& Brooks-Immel, 2019). Traditionally known as 'white universities' and 'white campuses', these educational institutions have been around in the United States since Harvard University opened its doors in 1636 (Brunsma, Brown \& Placier, 2012, p.719). Even after 50 years of post-civil rights movements, these 'white universities' and 'white campuses' continue to exist through "hierarchical structures and fundamental inequities" (Murray \& Brooks-Immel, 2019, p.162).

Within the Canadian context, Mohamed and Beagan (2019) assert that although Canadian post-secondary institutions "welcome diversity" they continue to operate from an institutionalized whiteness framework that is aligned with Eurocentric ideologies (p.340). Nakamura (2019) clarifies that these "Eurocentric" and "White-centric" ideologies act as the "norm" amongst post-secondary institutions and perceive all other cultures and people as "Others" through the legitimization of European based knowledge (p.50). Moreover, educational institutions situate White students to be ignorant about structural racism (Yeung, Spanierman \& Landrum-Brown, 2013, p.17) by engulfing students within walls of whiteness to shield them from attacks on white supremacy (Brunsma, Brown \& Placier, 2013, p.718). Schulz and Fane (2015) argue that tertiary institutions are known to demote questions of whiteness and race within their curriculum to prevent students from becoming critically conscious of whiteness and racial discrepancies within academia (p.137). 


\section{Racism}

The concept of race and racial hierarchy was invented during a time period in human history called modernity. During the 1600s, European empires "laid the foundation for the global spread of capitalism and imperialism" by developing agricultural societies in the Americas and the Caribbean (Foote, 2013, p.ix). Consequently, these expansions brought forth the invasion and attack on Indigenous Peoples and paved the way for the enslavement of African people as labourers (Foote, 2013, p.ix). Canada has its own 206-year history of slavery (Howard, 2018, p.848). However, the dominant narrative has been to portray Canada as a nation that operated in a 'democratic' matter towards slavery and that it did not encompass the overt misuse of power, punishment, coercion and repression in which was evident within slavery in the US (Howard, 2018, p.848).

Although acts of racism are severely criticized and disapproved within Canadian public discourses, racism is present however in more subtle ways and in the form of institutional racism (Marom, 2019, p.321). Gillborn (2006), declares that institutional racism consists of the collective failure of an organization to provide an appropriate and professional service to people because of their colour, culture, or ethnic origin. It can be seen or detected in processes, attitudes and behaviour which amount to discrimination through unwitting prejudice, ignorance, thoughtlessness and racist stereotyping which disadvantage minority ethnic people. It persists because of the failure of the organization openly and adequately to recognize and address its existence and causes by policy, example and leadership. (p. 85)

Moreover, Schulz and Fane (2015) assert that even though racism performs in subtle ways, institutional racism is very much visible at all levels in academia (p.138). Charbeneau 
(2015) proclaims that institutional racism is manifested in the 'hidden curriculum' (p.656). The hidden curriculum is revealed throughout "admissions criteria, curriculum requirements, graduation standards, residence hall arrangements, and other formal and informal policies and practices" within higher education (Charbeneau, 2015, p.656). Equally, Mohamed and Beagan (2019) maintain that institutional racism in post-secondary institutions is also manifested through the lack of racialized administrators and tenured professors (p.340). A 2001 report on employment practices was conducted on the recruitment, promotion and staff development amongst higher education. The study indicated that there were visible "ethic differentials in both short listing and appointments" (Pilkington, 2013, p.229). The report discovered that both "Black and Asian candidates were less likely to be short listed and appointed than White candidates" (Pilkington, 2013, p.229).

Han and Leonard (2017) assert that there is a hidden agenda of tertiary education avoiding critical discussions on institutional racism, whiteness and white privilege (p.116). By refusing to acknowledge institutional racism and whiteness, higher education creates a false narrative that racism does not exist and elicits a colour-blind society that believes that racism has been abolished (Han \& Leonard, 2017, p.116).

As a result, anti-racist frameworks are building momentum in tackling institutional racism amongst higher education. Dei (1996) defines anti-racism as an "action-oriented strategy for institutional systemic change that addresses racism and other interlocking systems of social oppression" (p.252). By centering race as the focal point in responding to institutional racism, it will provide insight into the inequalities of class, gender, sexuality and ability and how these identities may intersect with race (Pon, Gosine, \& Phillips, 2011, p.392). 


\section{Lack of Representation}

Many scholars have identified power discrepancies among faculty at educational institutions that privilege white faculty over "Others" and tokenizing representatives to diversify homogenous spaces (Hikido \& Murray, 2016; Marom, 2017). Studies have shown that $80 \%$ of US professors are overwhelmingly white (Pucher \& Roseboro, 2011, p.378). Post-secondary institutions in North America promote themselves as 'multicultural'; however, subtle acts of racism, colonialism and white supremacy continue to be embedded within their discourses (Marom, 2019, p.320). Tertiary education create spaces that center white students' voices over racialized faculty who frequently have their authority interrogated and contested in white classrooms (Puchner \& Roseboro, 2011, p. 377). Marom (2017) and Hikido and Murray (2016) affirm that post-secondary institutions use multiculturalism as a tool to promote diversity amongst faculty and their establishments; however, simultaneously preserving and supporting the status quo by employing white bodies in power within these educational institutions.

There are many critiques of multiculturalism amongst scholars, which offers an essential lens to whiteness and the culture of academia. Scholars assert that multiculturalism points to the lack of accountability to colonialism that benefits and upholds whiteness (Tanner, 2018; Marom, 2017). Moreover, there is a failure on the part of multiculturalism to acknowledge the various power relations and structures that create and reproduce inequalities for numerous cultural groups (Marom, 2017; Tanner, 2018;).

In Canadian discourses of racism and colonialism, these terms are often subsumed or silenced by the prevailing liberal discourse of multiculturalism; policies and practices under the multicultural umbrella ignore the structural and institutional level of racism and colonialism (Marom, 2017, p.165). Multiculturalism, therefore, "causes educators to partake in neoliberal 
endorsements of colonial essentialism" (Tanner, 2018, 81). Additionally, the 'language of diversity' within academia and multiculturalism does not parallel to significant challenges to the colonial and racial structures (Marom, 2019, p.320). The literature argues that academic institutions are more "concern[ed] about changing the perception of whiteness than it is about changing the culture and organization of the institution" (Mohamed \& Beagan, 2019, p.340).

\section{Pedagogy Practices}

White people often have difficulty seeing beyond the veil of race as whites do not think of themselves in racial terms, therefore concepts of race and whiteness are incompatible (Bohonos, 2019; Brunsma, Brown \& Placier, 2012; Leonardo \& Porter, 2010). However, people of colour are well informed that whites encompass a racial group; however, the discovery of this notion would require whites to confront their ignorance and expose themselves as racist (Leonardo \& Porter, 2010, p.150). Therefore, white educators shield themselves by tactics such as colour-blindness that prevent them from acknowledging their own racial frame and its implication for racialized students. Subsequently, Charbeneau (2015) asserts that pedagogy practices remain to serve whiteness consciously or unconsciously (p. 656). White teachers resist learning about race because of their possessive investment in whiteness (Matias, Viesca, Garrison-Wade, Tandon \& Galindo, 2014, p.290). When authentic race dialogue does occur, it runs the danger of being forced as an ideology as well as running the risk of patronizing racialized groups (Leonardo \& Porter, 2010, p.149-150). Moreover, race dialogue caters to the white racial frame in what Leonardo and Porter (2010) call the 'white imaginary"; an imaginary that allows race dialogue to be accepted but only in small amounts (p.149).

However, Puchner and Roseboro (2011) extend a caution to educators who discuss racism and whiteness with their white students (p.379). They maintain that it can become 
severely problematic and cause the opposite effect as these discussions can often avoid personal responsibility (Puncher \& Roseboro, 2011, p.379). Therefore, Puncher and Roseboro (2011) argue that discussions on racism and whiteness in classrooms can lack any real transformation as the 'attention' is centered towards white people and how to accommodate their lives rather than addressing white people's racist ideologies and discriminatory practices (p.379).

\section{Colour-blindness}

Another significant theme highlighted in the literature explored pedagogical practices among post-secondary professors. Numerous scholars discussed that although many educators are committed to an inclusive pedagogy practice they are, however, often diluted by colourblinded approaches of 'not seeing race' which reflects the denial and ignorance of whiteness within pedagogy practices (Applebaum, 2005; Bohonos, 2019; Brunsma, Brown \& Placier, 2012; de Freitas \& McAuley, 2008; Flintoff \& Dowling, 2019; Leonardo \& Porter, 2010; Matias \& Mackey, 2016; Todd, Spanierman, \& Aber, 2010). Although colour-blindness may at times be unintentional, it can, however, perpetuate racism (Applebaum, 2005, p.282). "Color Blindness"1 or "colour-blind racism" is the "insistence that individuals do not or should not see race because race no longer matters" (Bohonos, 2019, p.322). Moreover, colour-blindness refers to the "denial, distortion, and minimization of race and racism" (Todd et al., 2010, p.98). It follows a series of attitudes and ideologies that replicate various forms of racism and white privilege (Todd et al., 2010, p.98). Applebaum (2005) explains how educational institutions and educators in

\footnotetext{
${ }^{1}$ It is important to acknowledge that although colour-blindness approaches are racially driven, it is equally very much an ableist act that reinforces prejudice and discrimination against individuals with disabilities. There are over 250 million people who suffer from colour-vision deficiency (CVD). Supplement data is available. See Campbell, F. A. K. (2008). Exploring internalized ableism using critical race theory. Disability \& Society, 23(2), 151-162 and Shen, W., Mao, X., Hu, X., \& Wong, T. (2016), Seamless visual sharing with color vision deficiencies. ACM Transactions on Graphics (TOG), 35(4), 1-12.
} 
those establishments pride themselves as progressive; however, colour-blind ideologies limit diverse curriculums in classroom settings (p.283).

As a result, the veil of colour-blindness becomes a safe haven; an ideology that refrains "we're all the same underneath the skin" at the expense of marginalized groups (de Freitas \& McAuley, 2008, p.431). de Freitas and McAuley (2008) argue that a colour-blind attitude is detrimental to marginalized groups as it fails to recognize the profoundly different lived experiences of individuals who know about inequality and racism (p.431). Applebaum (2005) asserts that one who can assume to be colour-blind acts through a place of privilege in which only the dominant group can endorse (p.284)

\section{Limitations}

There are several knowledge gaps in the literature. The majority of the literature focused on the experiences of racialized and white faculty in mainstream institutions. Although some of the literature did highlight the norms and practices of post-secondary institutions, there was an absence of white students' understanding and experiences of whiteness in educational establishments. Another gap in the literature pertained to the lack of race-based data collection. While various geographic affiliations provided insight into the matter, the majority of statistical data found in the literature was collected by American scholars on American post-secondary institutions. It was challenging to acquire Canadian literature that contained race-based data, as many post-secondary institutions in Canada do not collect data on racialized students or faculties (Shibli, 2019, p.3). This is also the case with Statistics Canada and provincial government institutions.

A limitation amongst the literature revealed itself in self-disclosure. The researchers occasionally and at times never situated themselves in their research. When disclosure of the 
researcher's social location was included, it usually involved a generic response to the researchers' race, gender, and affiliation. As a result, the construction of the knowledge around whiteness becomes problematic as the researchers discuss advancements in the elimination of white supremacy in academia; however, they do not disclose their own implication in whiteness. Moreover, I would argue that critical self-reflexivity amongst the authors was not utilized indepth within their studies. Engaging in critical self-reflexivity throughout your research promotes an "on-going, recursive relationship between the researcher's subjective responses and the intersubjective dynamics of the research process itself" (Probst, 2015, p.37). Researchers need to be aware of the influence they have on the research and the participants being studied. The lack of critical self-reflexivity can produce misinterpreted experiences, interpretations, and biases on the part of the researcher.

Lastly, the literature that involved narratives from racialized individuals failed to construct knowledge on the power dynamics that were evident within the data collection and neglected to acknowledge any impact that their research might have had on the participants. Historically research paradigms were grounded in Eurocentric ideologies that were influenced by white supremacy and colonialism. As such, these epistemologies promoted a myth of objectivity by positioning research paradigms by white scholars as the true knowledge. Consequently, researchers ignored their footprints in the system of white supremacy and settler colonialism and excluded the stories and experiences of racialized communities and individuals. In this regard, the literature that involved collection of data from racialized individuals did not acknowledge the power structures that divided the research and the participants and ultimately contributed to the silencing of the marginalized voices. 


\section{CHAPTER 3. THEORETICAL FRAMEWORK}

The theoretical frameworks utilized in this study were critical whiteness studies (CWS) and critical whiteness pedagogy (CWP). CWS and CWP fall under modern critical social work theories, which asserts that "macro-social structures shape social relations at every level of social life" (Healy, 2014, p.185). A modern critical social work theorist works to understand the "structural conditions that impact on the genesis and maintenance of social problems" and identifies injustices that stem from differences in power (Healy, 2014, p.184). In this chapter, a clear definition of each theory will be outlined, and an exploration of its significance to this research study will be explored.

\section{Critical Whiteness Studies (CWS)}

CWS is considered a relatively new but rapidly growing framework amongst scholars. Early studies in CWS focused predominantly on "ethnographic accounts and personal narratives" of scholars and participants (Yee, 2017, p.61). However, CWS has evolved since its early stages of a concept. CWS now emphasizes "critiquing Western institutional, state, and ideological belief systems that maintain white privilege through the deployment of whiteness strategies" (Yee, 2017, p.61). Its main objective is to reveal and disrupt the invisible structures that "produce and reproduce white supremacy and privilege" (Applebaum, 2016, p.1). However, there have been many criticisms from scholars as to whether or not CWS effectively addresses the core problem of white supremacy and white privilege and scholars have argued for a

progressive CWS that tackles issues of white supremacy (Yee, 2017, p. 61). As a result, CWS is evolving and entering a "new wave" as a theoretical framework. This new and progressive CWS emphasizes and addresses the "limitations of essentializing race, advance arguments around 
racism within broader theoretical frameworks, and connect power, ideology and white hegemony, to illustrate how whiteness is perpetuated and internalized" (Yee, 2017, p.61).

As highlighted earlier, white norms have been socially constructed within mainstream society that privilege white bodies. CWS rejects these discourses and examines whiteness and the structures that uphold white privilege (Applebaum, 2016; Flintoff, \& Dowling, 2019; Hikido, \& Murray, 2016; Matias, \& Mackey, 2016; Nayak, 2007). CWS is a theory that assumes certain aspects of racism are connected to white supremacy (Applebaum, 2016, p.1). Nayak (2007) clarifies the three fundamental beliefs of CWS, which are:

1. Whiteness is a modern invention; it has changed over time and place.

2. Whiteness is a social norm and has become chained to an index of unspoken privileges.

3. The bonds of whiteness can yet be broken/deconstructed for the betterment of humanity (p.738)

Today, CWS offers a "radical intervention into race thinking and holds out the possibility to challenge and subvert the idea of whiteness as a universal norm" (Nayak, 2007, p.738). It has become a framework that deconstructs the "physical, emotional and political power of whiteness" (Matias \& Mackey, 2016, p.35). Moreover, CWS is beneficial in how we have theorized the white imagination (Matias, Viesca, Garrison-Wade, Tandon \& Galindo, 2014, p.291).

However, CWS does not mean to draw attention away from the experiences of people of colour. Instead, it seeks to address and critique whiteness as a contributor to the formation of racism (Bohonos, 2019, p.316). Moreover, CWS scholars assert that in order to understand "interactional and institutionalized racism" attention must be given to those of the dominant group who benefit from these privileges in addition to the victims of racism to fully grasp the 
systematic power of racism (Hikido \& Murray, 2016, p. 391). Therefore, CWS challenges the assumption that White experiences are 'normal' and 'neutral' (Bohonos, 2019, p.316). Rather, it provides a framework for understanding "why whites believe they are not part of race when they actively invest in white racial production" (Matias et al., 2014, p.291).

Moreover, CWS claims marginalized groups continue to be discriminated against because of the avoidance of whiteness by dominant whites (Bohonos, 2019, p.316). Matias et al. (2014) argue that this avoidance of whiteness is implicated in the refusal to acknowledge whiteness historically, economically, and politically, which has maintained a racist system and a contributor to the prevalence of race and racism (p.291). Therefore, CWS looks to examine those cultural practices and strategies that are employed by whites and seeks to find alternative realties that can be established to combat the invisible structures of whiteness that produce and reproduce white privilege (Hikido \& Murray, 2016; Murray \& Brooks-Immel, 2019).

\section{Critical Whiteness Pedagogy (CWP)}

Drawing from CWS, scholars have supported the development of a critical pedagogy of whiteness (Yeung, Spanierman, \& Landrum-Brown, 2013, p.18). As a result, CWP was formed to critique, confront, and change whiteness by requiring educators to tackle perceptions and practices overlooked by white students (Yeung et al., 2013, p.18). It positions educators, especially those who are white, to critically reflect on their own whiteness and how applications of whiteness create harsh conditions for people of colour (Matias \& Mackey, 2016, p.35). However, CWP does not limit critical reflexivity to merely educators. The onus is also on white students to critique and challenge their whiteness and whiteness in academia as well.

A key challenge in applying CWP amongst white educators and students is their strong attachment to whiteness. As Nayak (2007) affirms, white people do not see themselves in 
relation to the colour of their skin but by nationality, employment, age, and sex (p.737).

Therefore, critical reflexivity, self-awareness, and engagement (Yeung et al., 2013, p.18), which are tenets of CWP, can be challenging when there is a lack of ownership to whiteness.

Additionally, classrooms lead by CWP can have a sequence of emotional reactions amongst white students, such as guilt, discomfort or resistance that can prevent engagement in CWP (Nichols, 2010, p.6). Therefore, CWP has the potential to analyze racial injustices and should not be discouraged because of comfortability or convenience. Moreover, CWP challenges white students' assumption that racial injustices concerns are only applicable to racialized individuals (Yeung et al., 2013, p.19). Yeung et al. (2013) maintain that by positioning whiteness at the center of pedagogical practices enables white students to critically examine their own individual analysis of racial justice and how they are contributors to the injustices (p.19).

In this regard, CWP has four primary objectives. The first objective looks to analyze and define whiteness and recognize how it is preserved and not merely the individual choices made by white people (Nichols, 2010, p.4). Educators and students first need to acknowledge that whiteness is socially constructed with severe consequences for marginalized groups (Yeung et al., 2013, p.18). To do so, an examination of the historical foundation of whiteness is vital in exploring the development of whiteness throughout society (Nichols, 2010, p.4). The objective is met when educators and students "begin looking at Whiteness not as simply a category of identity, but as a position of power formed and protected through colonialism, slavery, segregation, and oppression" (Nichols, 2010, p.4).

CWP's second objective emphasizes the advancement of critical awareness of systematic forms of racism and white privilege throughout everyday behaviour and practices (Yeung et al., 2013, p.18). A vital component of this objective is examining the value and maintenance of 
whiteness (Nichols, 2010, p.4). The third CWP objective evaluates the intersecting characteristics that influence whiteness (Yeung et al., 2013, p.18). The focus is positioned on the various systems and processes that intersect with white identities that produce marginalization and oppression (Nichols, 2010, p.5).

The final objective of CWP draws on an individual's commitment and development to a "healthy White identity" (Yeung et al., 2013, p.18). This entails white educators and students to foster a progressive identity in which they may mobilize with various racial groups in the spirit of authenticity and compassion, as opposed to regressing to conservatism (Nichols, 2010, p.6). Additionally, white educators play a significant role in fostering white students' progressive identity by acting as mentors through the reflection of their own white identities and their journey in developing a healthy white identity (Nichols, 2010, p.6). 


\section{CHAPTER 4. METHODOLOGY}

\section{Narrative Approach to Qualitative Research}

The study utilized a narrative approach (NA) to research as its methodology to analyze and understand the stories as expressed by individuals (Creswell, 2013, p.70). NA can be interpreted as a "spoken or written text giving an account of an event/action or series of events/actions, chronologically connected" (Creswell, 2013, p.70). The premise of NA is that "speaking and writing are forms of meaning-making" (Padgett, 2017, p.39). O'Neill (2013) explains that narrative inquiry researchers:

...interrogate intention and language - how and why incidents are storied, not simply the content to which language refers. For whom was this story constructed, and for what purpose? Why is the succession of events configured that way? What cultural resources does the story draw on, or take for granted? What storehouse of plots does it call up? What does the story accomplish? (p.390)

Furthermore, the researcher engages in an inquiry through dialogue or questioning of the participant(s)' experiences of a phenomenon. They take an active role in the "restoring" of the stories (Creswell, 2013, p.74). As such, restoring is understood as the process of rearranging the narratives into a universal framework (Creswell, 2013, p.74). There are many components to NA when conducting research; however, not all narrative approaches are comprised of these elements (Creswell, 2013, p.71). According to Creswell (2013), NA:

- Provides individual lived and told experiences.

- Is a collaborative interaction or dialogue between the researcher and the participant(s).

- Contains turning points; may shed light on the identities of the individual(s) and how they see themselves. 
- NA stories are analyzed in three ways: thematically in which researcher identifies themes told by participants; structural in which the nature of the story shifts to telling; and dialogic/performance in which the focus of the story is turned to how is it produced and performed (p.71).

There are many strengths in utilizing NA of inquiry in research studies. Primarily, as noted, the research focuses on the "real-life" individuals' interpretation and translation of the experience. Furthermore, it analyzes the phenomenon in the context of broader social and political dimensions without diminishing the individual's story of their experience. At the same time, NA challenges dominant discourses by providing alternative narratives to the phenomenon.

As such, NA works best while studying a small sample of participants (one or two) and interpreting and gathering data through the collection of their stories (Creswell, 2013, p.70). NA has helped me conceptualize the human experiences of three RU white students who I interviewed. Furthermore, it has provided me with an in-depth exploration into the stories and experiences of these white RU students and how they make sense of the phenomenon, as well, how they see themselves in relation to the phenomenon.

Despite the benefits of utilizing NA, there are many challenges while using this approach. Researchers employing NA need to have the ability to clearly comprehend the circumstances of the individual's life. The research must recognize the essential material in capturing the stories of individuals' lived experiences (Creswell, 2013, p.76). Inability to do so results in the deficiency in grasping the essence of the stories, which can hinder the research study. Another challenge imposed by NA concerns the collaboration between the research and the participant(s). The researcher needs to actively be "reflective of their own personal and political background, which shapes how they "re-story" the account" (Creswell, 2013, p.76). If the researcher does not 
engage in critical reflexivity during their research, personal biases, judgement, and opinions may become visible through the re-telling of the story.

Additionally, if the researcher exhibits hostility towards the participant, it may cause challenges, especially if the participant may not wish to have certain aspects of their story published. As such, NA raises many ethical questions in terms of "who owns the story? Who can tell it? Who can change it? Whose version is convincing? What happens when narratives compete? And as a community, what do stories do among us?” (Creswell, 2013, p.76).

Thereby, to mitigate the ethical concerns raised by NA, this research study utilized member checking with the participants to obtain their feedback before the submission of this research paper. Member checking entails presenting participants with a draft of the MRP for the purpose of obtaining their feedback. This is a collaborative engagement involving the researcher and participant(s) that entails discussions of any concerns, questions or alternative analyses that the participant(s) may have. The goal of member checking is to ensure that I have not misunderstood or misrepresented what the participants shared with me.

\section{Major Research Questions}

The study focused on three primary research questions: 1). How do white students attending Ryerson define whiteness? 2). How do white students attending Ryerson understand whiteness in academia? and 3). How have white students attending Ryerson perpetrated or fought against whiteness within their institution? The main objective of the research is to: capture three white RU students' perception of whiteness, analyze their understanding of whiteness in academia and explore whether they have either perpetrated whiteness or resisted in the classroom. 


\section{Recruitment and Sampling Method}

The participants for this research study were recruited online through the creation of a flyer posting (Appendix A) and by a recruitment script posted on social media outlets such as Facebook (Appendix B). Enlistment of participants was employed using purposive sampling in which the researcher selects "respondents based on their ability to prove the needed information" (Padgett, 2017, p.68). There are various forms of purposive sampling that a researcher can utilize throughout the recruitment process. This research used criterion sampling, which involves selecting individuals that meet some predetermined criterion or norm (Padgett, 2017, p.68).

Participant(s) of this research were currently enrolled in a part-time or full-time program other than Social Work at RU. The rationale for the exclusion of Social Work students from RU was because discussions on whiteness, power, oppression, racism, and privilege are deeply embedded in the program structure. Thus, my curiosity extended to what were the experiences of white students at RU, who are in other programs, vis-à-vis whiteness.

Participants in this research study all identified as white English speaking. The researcher collected personal information such as the participant's name, phone number and email address to facilitate interview availability and to further aid communication throughout the recruitment process. Upon recruitment, the researcher clarified the research study's purpose and highlighted potential individual and group risk to the participant(s).

\section{Data Collection, and Analysis}

Data collection for this research was in the form of a semi-structured individual telephone interviews using an interview guide (Appendix C). Semi-structured interviews provide flexibility throughout the interview process, as it solicits more in-depth conversations or dialogue with the participant(s). Primarily, semi-structured interviews begin with developed research questions to 
start the interview process but will canvass additional information depending on the responses to initial questions or not use them at all (Faulkner \& Faulker, 2014, p.98). The flexibility of semistructured interviews allows the researcher to capture an in-depth analysis of the lived experiences and stories of the participant(s).

The interviews lasted between one to one and a half hours and took place over the telephone. The interviews were audio-recorded for the purpose of transcribing the data. Each participant signed a consent form (Appendix D) that listed potential risks, details of involvement in the study, and authorization for me to record their stories. Pseudonyms were assigned to participants.

After receiving participants' approval of their respective interview transcript, data analysis commenced. Data analysis used by narrative researchers "extracts themes that hold across stories" which are often referred to as taxonomies (Creswell, 2013, p.72). Thus, this research extracted themes that reoccurred during the interviews.

\section{Participants Profiles (using pseudonyms)}

Three individuals were interviewed for the research. Two participants identified as female and one identified as male.

Participant 1: Iris is a female student who is enrolled in Biomedical Science full-time at RU.

Participant 2: Steve is a male student who is enrolled in Business Management full-time at RU

Participant 3: Lyra is a female student who is enrolled in Architectural Science full-time at RU. 


\section{Ethical Considerations}

A proposal of this study was reviewed and approved by the Ryerson University Research Ethics Board (Appendix E). Although this research study has very low potential risks, due to the personal nature of the questions asked, a participant may reflect on unpleasant memories or experience feelings of discomfort, embarrassment or exposure while responding to the questions. Participants were informed before the interview that they could ask to stop or pause the interview at any time to suit their comfort. Further, they were provided with the option to withdraw from the study at any time with no repercussions.

As well, participants were informed that there may be a risk to participants partaking in telephone interviews. Although, the risk is low, there was a possibility that the participants may be heard during their telephone interview depending on where they are during the telephone interview.

Additionally, given that this research study pertains to RU students, a potential group risk may be involved. Participants were informed that there might be a possible group risk in being identified as a group of individual(s) in a specific program. This type of group risk is, however, minimal or no harm will come to group members. Additionally, to protect the participants confidentiality, only participants name, program and length of the program was obtained. Any other data such as age and what year the participant is in may have put the participant at further group risk. 


\section{CHAPTER 5: FINDINGS}

Five central themes materialized out of the analysis from the data. These themes which will be discussed in this chapter are 1). Being White... What does that Mean? 2). Patriarchy, 3). What About Us? 4). Exposure to Whiteness and, 5). Moving Forward.

\section{Theme \#1: Being White...What does that Mean?}

\section{Defining Whiteness}

The participants shared their knowledge and understanding of whiteness. The data revealed that each individual had their own personal attachment and relation to the term which affected their interpretation of whiteness. For instance, Lyra, expressed whiteness as,

"a term used to describe individuals that are white, that believe and behave like they are the best, they know everything".

Her definition ties whiteness to a belief system and a behaviour in which only white individuals can acquire. Lyra reveals that "although society is very much diverse, white people continue to be privileged, or receive special treatment as oppose to other difference races". Lyra acknowledges that whiteness is associated with systematic structures that "privilege white people", whereas, Steve's and Iris' definition of whiteness are the total opposite. Both these participants shared that the term whiteness does not "mean anything" and that it does not hold any tangible value to them. In particular, Steve who disclosed that he is of Eastern European decent and visits Europe often, expressed that,

"to be honest, it does not mean much to me. Just because I am white, but I'm of European descent and Europe is very diverse. So, I think that, you know, it's similar to a white person going to somebody that's black and saying, you know, you're African American when they could really be Cuban. They could be from Panama; they could be from South America. So, I think it's, to me doesn't mean anything that much. I think it's something that we've kind of already constructed in North America." 
Through his description, Steve understands whiteness as something that is only located and specific to North America and is sustained through the discourses and ideologies that are associated in North America. He shared that Europe is a "very diverse place with many different cultures, histories and traditions", therefore, he explained, that discussions about whiteness where "non-existent" due to the fact that "you can't just place all white people in a pot, especially in Europe, we are all so different".

Similarly, Iris who also disclosed to be of Eastern European decent, offered her description of whiteness. She shared that to her whiteness "means absolutely nothing" because “she does not see colour”. Iris' definition reflects de Freitas and McAuley (2008) ideology on 'not-seeing-colour' that assumes "we're all the same underneath the skin" (p.431).

\section{Privilege}

As the discussions on whiteness progressed, privilege became a reoccurring theme amongst the data. As white individuals we receive unearned entitlements or immunity because of the basis of our race or social factors. Often referred to as an "invisible knapsack of unearned assets", privilege are the taken-for-granted advantages of being white (Applebaum, 2016, p.6).

Each participant was asked to reflect on the term privilege. Overall, the participants understood privilege as "having an advantage over someone" or "receiving special treatment". When asked what 'that' advantage might be, both Steve and Lyra expressed that it can be "based off anything" and "can affect anything". However, Steve explains privilege through the analysis of a "third person perspective" in which he clarifies as "looking at yourself" in making your privileges more visible. He explains,

"privilege may not be visible in your eyes. I think that some, if you have privilege, it's tough for you to actually see it. You kind of have to look at yourself from a third person perspective, in order to basically see, see that happen." 
When asked whether the participants saw themselves as privileged individuals because of their whiteness each participant had different responses. In particular, Steve explained that to be privileged is a "subjective question" which is also "situational". He states,

"I think it's easier to ask somebody who doesn't have privilege what somebody else's privileges are because you see that, right? I don't think I would be able to tell you my privileges. I think that I'd be biased in that."

Similar, Lyra acknowledges that she may have some privilege but explains that privilege is "situational" as well. She states,

"yes, in certain situations yeah, I do feel that I have more of a privilege as opposed to somebody who has a different race or racial background."

When asked to provide an example of a situation where the participant might be privileged, both Lyra and Steve explained that there are certain "stereotypes", or "preconceive notions" attached to white individuals that associate white people as "responsible", "trustworthy", "friendlier" and "being able to hold a job". In particular, Lyra shares that there have been situations where she felt people did not "fear" her because of her whiteness. She states,

“sometimes I feel like people aren't afraid of me because I'm white, but they feel intimidated or afraid of someone with a different ethnicity".

In contrast, Steve acknowledges that these attributes are "advantages of being white" and have "helped me out in the long run", however, explains everyone has privileges. He states, "you [the interviewer] as a female, you [the interviewer] have privileges and enough of minorities have their own privileges"

However, Iris expressed that she "does not believe in privilege". When asked why, she explains that we live in a diverse city such as Toronto and the city's diversity is displayed throughout RU. She explained that she has worked in numerous settings where she "never 
worked with another white person", therefore questions whether white privilege is real since she's worked in numerous settings with vast diversity. Instead, Iris believes that there is an "aim of propaganda towards white privilege". However, Iris acknowledges that she can "see that as a bias" because she is white. On the other hand, she disclosed that she does not feel "exactly privileged" either because of her whiteness. Instead, she considers her identity as a female as the “only reason I get by".

\section{Theme \#2: Patriarchy}

\section{Historically/Socially}

Discussion on patriarchy was dominate amongst the participants. Each participant discussed how gender influences the way we interact with one another and how one is perceived especially in terms of whiteness and privilege. Each participant expressed that male dominance and patriarchy is linked to colonialism which is now ingrained within our society. Steve explains,

"historically, I think it dates back to Western Europe being a powerhouse and you know these countries were the global dominate players and they were white, male, you know, this is why people kind of have this tendency to associate whiteness with power or, or having an advantage or strength or whatever".

Both the female participants Lyra and Iris shared that it is "easier for white males" in today's society to "move up" or "speak out" about socially and political issues. Lyra explains, "definitely white males have more of an upper hand, yes, advantage over white females. I guess because this is a Western society. We are a very male dominated society. It's very hard for women to move up on the ladder."

She acknowledges that all women despite cultural background are seen as "second-hand citizens" in comparison to white males in Western society. Moreover, Lyra explains that despite whiteness and privilege associated with white women, she finds that white women have to work "ten times harder to get to the standard point of where a white male should be." 
Whereas Iris disclosed her previous career choice was becoming a nurse which she shared was inspired by her parents who believed that nursing was considered a "job for a woman". She shares,

"everything I did in high school was towards a nursing degree... and nursing was really inspired by my mom and dad who really thought that was like a job for a woman. I hated it."

Iris explains despite being positioned to follow a "woman" career degree, she dropped out and chose a "radical pathway" as she applied for her current field in Biomedical Science.

\section{Within Academia}

All three participants acknowledge that RU reflects the diversity of Toronto. Each participant shared that their program embodies the diversity of Toronto with its students, staff and overall campus life.

Lyra: "I find that my classes are very diverse. We have people from many areas of the world in all of our classes that you could think of."

Iris: "Especially my program, yes. Well, in all fairness, my program is consisted of $70 \%$ non-white. I would say they have the biggest voice of them [non-white students] all."

Steve: "I believe Ryerson University diversity is reflected by different student group base and various nationalities and religion. Also, many of my Ryerson professors come from different backgrounds and cultures."

However, when the discussion diverted to patriarchy and whiteness in academia, each participant shared their knowledge and awareness on the discussion. Each participant expressed that their program does incorporate discussions on whiteness, however, they stated that these discussions are either through selected elective classes or in Steve's case involve modes that would "attract diversity in the workforce". He shares,

"there was also emphasis placed on if we want to operate in global marketplace, [then] our staff should be diverse like the world is." 
Similar, when the question was asked to Iris whether discussion of whiteness was incorporated within her program, Iris stated,

"Oh, yeah. definitely [in] my electives. We discuss white privilege."

However, Lyra on the other hand acknowledged that discussion on whiteness was not as transparent when compared to the other two participants. She stated,

"Whiteness?...we've had discussions about the industry itself and who's more dominant in the industry in terms of white individuals or individuals of different races, as well as males and females, things like that."

The data revealed that each participant experienced within their respective programs at RU discussions of whiteness as part of their curriculum. However, each participant shared that despite diversity being physically visible within RU, the intersection of whiteness and male dominance is silently present. In particular, Lyra shared that she feels gender discrimination within her program because it is a male dominated field and finds the white males in her program "have a little bit of an easier time than the females". She shares,

"I feel like even like the faculty are geared towards them [white males] because they believe I don't know and they [white males] will know more, so I have to work harder".

Similarly, Iris shares that she is often disregarded by the professors and states that white males "tend to speak up more". In contrast, Steve explained the rationale as to why academia continues to be white male dominated, especially in terms of senior management:

"take a look at the directors, the senior staff, who are they? Their around 60 or something years old, the schools were built over 50 years ago where during that time we were still you know, segregated or getting out of segregation. So, I guess it makes sense that the people that are currently in power are white males."

Each participant explained that majority of the perspectives within academia are historically Eurocentric ideologies. Steve, in particular, mentions that academia does not provide 
what he describes as a "second opinion" or a "challenging opinion" but instead maintains the status quo approach. However, he acknowledges that there are classes that are "slowly incorporating different viewpoints" through class readings or presentations. But he admits that academia itself is "predominantly influenced by Western European ideologies".

Similarly, Iris rationalizes that the reason the majority of current senior staff at academic institutions are white males is due to the historical make-up of academia. She clarifies that academic perspectives historically came from a "white perspective" and it came from a "privileged perspective" as education was only acquired and available to white males. Therefore, there was no room for other knowledges or different views. She states,

"it was the whites that had the privilege of, you know, taking 20 years to study anatomy or whatever is was... and definitely in terms of even the books sometimes they're written in a way that doesn't all entail all cultures"

Despite the historical make-up of white male academia, and its current senior positions being dominated by white males, Iris shares that many of the "millennial professors" are "moving away from that Eurocentric realization" and offering "different perspectives". Equally, Lyra shares that she has had discussions with her peers in other programs who have informed her that they have encountered "younger" professors who have incorporated "different perspectives". She shares,

"I have friends in other programs, and sometimes we get together and talk about school and which professors are hard or good and they say it all the time that the younger professors challenge them more in how they think."

\section{Theme \#3: What About Us?}

Surveillance /Self-regulating/Silenced/Invalidated

Each participant shared that they felt they were constantly being "watched" or "scrutinized" and therefore, consciously regulated their behaviour so not to be accused of being 
discriminatory, or racist. Lyra, for example discussed how she feels "silenced" and "defeated" when she is in situations where discussions about oppression, racism and discrimination does arise. She shares,

"I feel like I have to take it and shut my mouth, because if I see anything, then they're going to come back and say, "Oh, well, you know, white people have done this to like everybody else and you have no right to talk or open your mouth" so I feel like I have to be silenced a lot... like I have to watch what I say all the time."

Comparably, Iris explains that she "puts a lot of filtering" and "thought into what she would say". In particular, she shares she feels silenced when others make jokes about white people and laugh and feels as if she cannot say anything back. She shared that she has encountered these narratives and jokes on RU social media outlets where white people were the center of the jokes and she could not speak out against it. She states,

"even social media, which is a very common one at Ryerson, like you have common Ryerson groups were they always joke like, oh "white, white people be like this, this is a white person" you know and its, if they said that it's a joke, it's fun, it's everything but if a white person said that its like you're a racist or homophobic or whatever."

Iris describes these incidents as a "double standard" attitude towards white individuals. In particular, Steve explained that as a white, heterosexual male, he finds it difficult to "criticize" anyone in regard to academics, in discussions or employment. He shares,

"I think for me to criticize somebody, I can't do that publicly, because, you know, as a white heterosexual male, I think that my point is, not validated because of years and years of being on top that somehow, you know, Jack from 10000 years ago has kind of basically invalidated my point now, and just because he had power back in the day and identified as a white heterosexual male that, that's the only characters that I share with somebody that I don't even know and as a result now my points are no longer validated."

Therefore, Steve explains that because he is a white heterosexual male he is "constantly conscious" in how he speaks and his body language especially at school because he shares, 
"I know that I am being watched and ready to be criticized if I say something that may offend someone."

\section{Exclusion/Isolation}

The participants shared incidents where they have felt excluded or isolated at campus or in their program. Iris shared that although RU does an excellent job at promoting diversity and cultural groups, she nonetheless feels "excluded" because she is white. She shares,

"University is all about open ideas and creativity right; it's about being open to everything and it's about voicing all opinions, not just the minority one. And sometimes I feel like, you know like, they're promoting you know they're promoting like the African American, they're promoting LGBT, they're promoting Chinese, they're promoting this and you're really losing who you are. What if I don't identify with any of them, now what do I do?"

Iris explains that it can be isolating especially within her program which she disclosed composes of "70\% non-white" students. She shared that she finds it "difficult" to connect with her peers in her program. She disclosed that during group work her classmates would pair together base on similar cultural background and revealed that she "ends up" being paired with people who "kinda already exclude me [her]" because she may not share the same "opinions or views". Iris explained that situations as those make her feel "disregarded" and isolated.

Similarly, Lyra shared that there have been occasions where she wanted to participate in school activism at RU, however, due to the content she thought best that she should not attend. She shares,

"there was this one time where, you know Ryerson has so much social justice events or stuff going around campus and I thought it would be interesting to go but I decided not to because I thought my presence would not be wanted there."

In contrast, Steve shared that although he has not felt any personal exclusion or isolation at school, he did explain how there are festivals and events that do exclude white people. He stated, 
“personally, no I haven't felt any kinda exclusion or felt isolated. If any thing I would say you know, Toronto is so diverse and has many festivals and events, which sometimes does exclude white people. Like this one ad I saw for example, it strictly said "no white people", you know. Like what would happen if a white group said "no" to this culture or "no" to this race, there will be an uproar."

In contrast, Iris explains that she finds professors tend to be "kinder to non-white" students and "accommodates" their needs instead of white students. She provided an incident that occurred in her program. Iris explained that there was a time where she needed a religious accommodation, however, was not granted one. Although, she disclosed, that another student of a different religious background asked the same professor for a religious accommodation and was granted it. She states,

"the professor granted that [other student] accommodation but they didn't grant [it] for me. For me they said "You should have thought about it before you had two weeks to think about it. That is not our problem", which I felt was unfair because I'm not a minority? Right, I'm not gonna speak out and be like "hey, I'm oppressed" and even if I do, no one's gonna care".

She explains that at times its infuriating as she too is an immigrant and "underwent everything they underwent". She states,

'I wasn't born here, I wasn't privileged here, I wasn't, you know raised her. I, I went through the bullying phase, I went through adapting phase. I went through all the immigrant phases and you accept that. But somehow because I am white, its totally disregarded and unacknowledged."

\section{Theme \#4: Exposure to Whiteness}

\section{Perpetrating /Intervening Whiteness}

Each participant shared that they unconsciously may have perpetrated whiteness at some point in their lives, whether it be in academia or in everyday occurrences. However, each shared 
that unless they were "observant" or "aware" of perpetrating whiteness, they believed nothing wrong of it. Steve expressed that,

"I feel unless you are really paying attention and being observant you won't see whiteness demonstrated."

In particular, participants Lyra and Steve both shared that they "may have acted" in ways that perpetrated whiteness, by participating in "stereotypical jokes" about other ethnicities, however, explained that these "jokes have been around forever" and that "everyone makes them". Lyra states,

"I guess you can say, that. You know, I am guilty of perpetrating whiteness. I have made the stereotypical jokes about other cultures, but I feel like everyone has. But I understand that these jokes can be harmful now that I am older, so I don't really joke around like that anymore."

Similar, Steve explains his experience of unconsciously perpetrating whiteness through participating in stereotypical jokes, he shares,

"I have made jokes about other cultures, you know, those stereotypes that everyone knows and does. It's not meant to be hurtful, just fun. I feel like it's not only white people that make those jokes, its everyone and also white people get made fun of too, so not sure if that is perpetrating whiteness."

Although, Steve could not decide whether stereotypes of other ethnicities were ways of perpetrating whiteness, he did however explain an incident where he "deliberately" and "consciously" acted on his ethnicity as an Eastern European male within his place of employment to "one up another employee" in order to "gain trust" from management who shared the same similar Easter European background. He shares,

"Let's see, the thing is that for me I feel that it wasn't necessarily whiteness, but I used my ethnicity as a kind of privilege. I've used it deliberately, consciously in order to kind of gain trust and this kind of ethnicity privilege to one up another employee. So yeah, in that perspective, yes, but I think generally as whiteness. That is hard to say. But in terms of ethnicity, then yeah, I would absolutely agree with that statement." 
In contrast, Iris explained her unconscious perpetration of whiteness was not necessarily an "act" but a "thought". She provided an example of an incident that occurred in which the media was covering a story regarding skin bleaching in India and many expressed concerns, however, Iris "thought" differently, she explains,

"I thought, you know at the beginning I was like, let the people do what they want. I was like, does that matter but then I caught myself and I was like, maybe not. Like their trying to match these white beauty standards. And I honestly don't believe in that...I don't see beauty as you know as a white standard beauty. But then I see media pressuring on that and the overall community right."

Iris explained that her initial thought might have been perpetrating whiteness, however, with critical reflection, she understood it as a bigger issue that is the product of white beauty standards and the media enforcing those standards.

The discussion moved towards feelings of discomfort when others speak about oppression, discrimination and whether the participants ever spoke out against these injustices. Each participant shared their own personal involvement and emotions.

Lyra explains situations where discussion about whiteness, oppression and discrimination invoked discomfort. She explains,

"sometimes certain situations make me, they make me feel uncomfortable. And I think it's because I don't understand, especially the historical part or I have lack of knowledge and I don't know what my position or stance is in all that."

Lyra provides a situation that occurred in one of her classes where she witnessed whiteness, however, did not feel comfortable disclosing the scenario. She explained that she did not intervene due to her discomfort but acknowledges that someone should have. She states,

"Yes, I do feel that myself or somebody else should have intervened. But at the same time, I, I didn't feel comfortable. And even if I [would] have intervened, I don't think it would have done anything." 
Lyra shared that it's "hard" to confront someone who is providing "special treatment" to someone else because they identify as white. She shares that they would "automatically deny it", get "defensive" or even "attack" her.

Similarly, Steve explained that depending on the "circumstances", he is unsure what he would do. He states,

"I mean, to be honest, like I can sit here and act as an angel and say "yes" but in reality, it's really tough. I don't know. I think you know these circumstances are so situational, it's tough to say."

Conversely, Iris shares that she would "definitely" stand up and speak out for injustices. As an immigrant to Canada, she shared that she received what she explained as "firsthand experience" in being identified as a newcomer and adjusting to Canadian norms. She explained that she understands how hard it can be at times. She states,

"I definitely believe in standing up for the weak, for the, for the minorities, for people who don't stick up for themselves."

However, Iris shares that her "standing up" has nothing to do with whiteness. Instead, she explains,

"I wouldn't intervene because it's another culture, I would intervene because its wrong, because intervening is the right thing to do. Not because I'm white and I have the privilege of doing that."

\section{Theme \#5: Moving Forward}

\section{Finding Solutions}

Each participant agreed that $\mathrm{RU}$ is doing their due diligence in finding solutions to address whiteness in their programs and on campus. Many shared examples of their program inviting "guest speakers" from different cultural backgrounds or incorporating "diverse readings" 
into the syllabus which offered "diverse perspectives". Each participant shared that RU does a good job at "promoting" and "investing" in its diverse campus life through the various activist initiatives that run throughout the semesters and social groups. However, each shared that at times it can be "overwhelming", "unproductive" and does not actually "produce any change" to the wider social political problems. In particular Steve explains that at times he feels that the need for solutions are "blown out of proportion" and schools contribute to these emotions. He shares,

"I think that some of the stuff is blown out of proportion. Some of the things, I think it's that, because so many things are blown out of proportion and schools are constantly enforcing these, these I don't know, "we need to change, we need to find ways to coexist", it's that over time you become, you become immune to it. I think that's a problem."

Steve explains that discussions on "racism" are "serious allegations," however, he clarifies that the media and academic institutions actually hurt these causes with its constant over illustrations of the issues. Therefore, Steve shares that these issues are not "tackled" justly, instead he explains that we become "immune" to these issues and "start ignoring" them. $\mathrm{He}$ explains,

"The problem is that a lot of things, when you hear it on the news or even at school, some of it is blown out of proportion. And the problem is, then you start to become immune to it, and then you start ignoring this, and then I don't think that the actual case becomes, we don't find solutions to the actual causes. I think there are people that that are affected, for example, I know from finance from this course, that in 2008, 2009 in America, many black applicants were rejected based on the color of the skin, not necessarily on their financial status. So, I agree that it's something that really does impact the world. It is unfortunate. But I think that the way people are tackling this is not headed in the right direction."

In a related vein, Iris and Lyra shared that they felt at times social issues are often too frequent or "overplayed" with constant engagement and focus on these issues. Iris shares that 
although she acknowledges the need for "engagement" and social justice issues to be addressed at RU, she shares that it can be a "bit eye rolling". She shares,

"I feel like it's a great idea for them. I think, to try to get out there to try to put on more people you know engage, engage. And I think it's great but also, you know, I've got so many years of Ryerson and they're doing this all the time, all the time, you know it's a bit eye rolling sometimes. I'm like okay we get it, we get it."

Conversely, Lyra acknowledges that we need to find solutions to create change to tackle whiteness and racism, however, she shares that "we're all going through a tough time" right now and "we're all trying to help other people" but the constant "display" or "disruption" actually hurts any cause. She states,

"I'm just gonna be truthfully, sometimes, like, is it overplayed. I find it's a little you know, I've had enough of it. I understand where everybody's coming from completely, but sometimes I feel like you know what, we're all going through a tough time. But we're trying our best to, you know, help other people, but sometimes I'm just fed up. Why do you need to I don't know, like protest or cause any sort of disruption? Again, I think sometimes depending on the situation that they're bringing up for example like race or gender equality or whatever it is, I feel like yeah, I get it but I feel a lot of people are sort of tired of hearing about it."

When asked whether she thought whiteness would ever go away Lyra explains that although it would be nice to "live in a world where white privilege doesn't exist", she shares that it is very "naïve" of us to think that would happen. She states,

"I think it's nice to think that we have this, you know, that we're all going to change and we're all going to have this mindset of you know that white privilege is going to be gone and that we're all going to be equals. But I think that's sort of naïve to think that. I think they'll always be there at some level."

When asked why she felt that there essentially was no hope in eliminating whiteness, she explained,

"because of years and years and decades of white individuals being dominant over everybody else, through North America and throughout the world and history shows that 
white people prevailed and to change that mindset of those individuals that narrow minded thinking, it would be ridiculously hard to change for everybody."

Iris explained that "white privilege is always mixed up with fear in a sense". She provides an example that she would not "call them straight out racist" those who are perpetrating whiteness because she clarifies that they are "uneducated" and "misinformed" about other cultures. Therefore, she shares that more is needed to be done to educate and inform white individuals of the diverse identities of other cultures and groups:

"you see white privilege is always mixed up with fear in a sense. I've been up north, and I wouldn't say that people are inhospitable or intimidating towards non-white, it's just they don't know the other cultures, they're not.. they're uneducated, they're misinformed on other cultures and so it just makes..., I wouldn't call them straight out racist. But a lot of people, just like at the beginning, even in Toronto, a lot of people are just misinformed and uneducated and people tend to fear people they don't know." 


\section{CHAPTER 6: ANALYSIS}

In this chapter, I will analyze the findings and link it to the current literature.

Additionally, I will illustrate any emerging patterns and examine any contradictions, limitations, and gaps within the literature. As a critical social worker, I will position myself within this analysis and reflect on my own comprehension of whiteness and explore how I have either perpetrated or intervened against whiteness.

The participants described whiteness through their own interpretation. Lyra defined whiteness as a behaviour and belief system ascribed only to white individuals that privileges them over non-whites. This finding aligns with Hikido and Murray's (2016) definition of whiteness that states whiteness is a dominant racial power that privileges white groups over racialized individuals. Lyra's interpretation associates whiteness solely on white individuals; however, as Matias and Newlove (2017) discuss, whiteness is not necessarily only equal to white people. Therefore, to distinctly link whiteness to white individuals is unfitting, as Matias and Newlove (2017) highlight how racialized groups can also preserve and execute whiteness. As Duhaney (2010) clarifies, the effects of whiteness positions white individuals to occupy specific spaces. By examining whiteness through this perspective, it brings forth just how unclear and undefined whiteness can be when asked to define it.

Another participant Steve discussed whiteness originating in Western Europe and later being constructed in North America. Through this understanding, the participant associated whiteness with a geographic location explicit to Western Europe and North America. These geographic locations have historical roots in colonialism, imperialism, and neocolonialism. This reflects the findings by Baffoe, Asimeng-Boahene and Ogbuagu (2014), who discussed that the roots of colonialism began in Europe and eventually paved its way to North America, and as a 
result, polices, practices and ideologies came along to "re-create white" colonies. However, to imply whiteness is solely constructed in North America does not allow room for self-reflexivity, instead it situates white individuals to ignore their own implication and preservation of whiteness. As Frankenberg (1993) explains, to speak of whiteness is to assign everyone in relation to racism (p.6). The author argues that racism has "shaped white people's lives and identities in ways that are inseparable from other facets of daily life," hence it may be more difficult for white people to speak out against whiteness (Frankenberg, 1993, p.6).

In contrast, Iris disclosed that whiteness meant nothing because she does not see colour. Through this understanding, Iris associates whiteness with pigmentation, a racial identity. Iris' understanding reflects Bohonos' (2019) discussion on colour-blindness where individuals do not see race as race no longer matters or exists as we live in a multicultural society that embraces diversity and inclusion. However, as Frankenberg (1993) explains, colour-blindness continues to be a "polite language of race" that despite its best intentions it "preserves the power structure inherent in essentialist racism" (p.142, 147). Furthermore, de Freitas and McAuley (2008) assert that colour-blindness is in fact harmful to non-white individuals as it neglects the lived experiences of racialized groups and assumes that we are all the same. Although most of the literature focused on educators' involvement in colour-blinded approaches, there is a limitation amongst the literature that highlighted students' contribution to colour-blindness practices. In my self-reflections, I realize that I too have inflicted a colour-blindness approach by looking past an individual's racial identity and assuming we are all the same. Long before my post-secondary education in social work I encountered an incident at work where I befriended a co-worker who was a Black female. We had many conversations about women inequalities and the challenges we faced as young mothers. However, through these conversations I assumed that our 
experiences were alike and disregarded her experiences as a Black young mother and the systematic challenges that she faced. I ponder whether I meant to make that individual feel more welcome or perhaps I wanted them to know that I was an ally by not recognizing their racial identity, and thus not acknowledging their experiences; however, through critical reflexivity, I recognize that I have unintentionally perpetuated racism through these acts.

The participants were asked to reflect on their definition of privilege and whether they felt they had any privilege. Each participant understood privilege as having an advantage over someone. Through this understanding, the participants explained that anyone could have privilege. Steve shared that to ask about someone's privilege is a subjective question, and to be privileged is also very situational. Steve presented privilege through the analysis of a "third person perspective", looking at yourself through the eyes of someone else. However, I contemplated if one were given the ability to see their privileges, would that be enough for that individual to change their perspectives on the realities of whiteness and white privilege? Conversely, Iris shared that she did not believe in privilege and that there was an aim of propaganda around white privilege. However, to not acknowledge white privilege, does that inherently make you privileged? White individuals seldom think about their privileges, whereas marginalized groups are constantly informed of their non-privileged status. Although the findings of Frankenberg (1993), de Freitas and McAuley (2008), and Hikido and Murray (2016) discuss white privilege as a social construction that centers and advances white individuals against non-white groups, the literature did not highlight how white individuals define white privilege and whether they see themselves as privileged bodies.

Alternatively, Lyra and Steve acknowledged their white privilege and disclosed situations where it has benefited them because they embodied "white qualities. They also spoke about how 
whites were associated with discourses such as "trustworthy, responsible, and friendly," which distinguished them against of racialized groups. Their discovery aligns with Nayak's (2007) discussion on whiteness functioning as a "cultural category" where to be respected one needs to embody "white qualities" and discourses that reflect the achievement and power of whiteness. Therefore, anyone who does not exemplify these "white qualities" are seen as "Other"; someone who does not want to conform to the ideologies and practices of whiteness. Comparably, Lyra associates her white privilege with fearlessness as she disclosed that people do not fear her because she is white; as to be white you are less likely to be seen as a threat. The dichotomy between fearful/fearless, and threat/trusting is the result of colonialism and anti-black racism that portrayed whiteness as the symbol of "goodness, virtue, beauty transcendence, and purity" and Black bodies were "equated with a Blackness that signifies evil, sinfulness, dangerousness and criminality" (Dyer, 1997, as cited in Phillips \& Pon, 2018, p.87, 90). These ideologies drew from Manicheanism which according to Dyer (1997, as cited in Phillips \& Pon, 2018, p. 90) is “a doctrine based on the ideas of the Persian philosopher Manes, which saw the world as polarised between forces of absolute good and evil, symbolised in the oppositions of light and darkness, black and white." Moreover, Phillips and Pon (2018) argue that due to "scientific racism, the Manichean binarism and the legacy of slavery, Blacks continue to be regarded as a danger to society" and to whiteness (p.91). This "fear" has unfortunately manifested in today's institutions such as policing, education, health, law and policies that profile individuals based on their colour of their skin and attach discourses that preserve whiteness. It has become more evident from the recent events surrounding the death of George Floyd, an African American man murdered by the police in Minneapolis. His death has evoked global cries to stop police brutality against Black bodies and a call to stop systematic racism. 
Gender was a significant factor in how each participant viewed themselves within the broader political and social structures and how gender is implicated in academia. It is important to re-state that two of the participants, Iris and Lyra, identified as female and the one participant, Steve, identified as male. The construction of gender and patriarchy is influenced by these three participants' identity, as was revealed in the data. When two of the female participants spoke about gender and patriarchy, they spoke of working harder than their white male counterparts, as well, white males being regarded as superior to white females. This finding reflects Torres and Pace's (2005) proclamation on whiteness having a gender and that gender is male. Similarly, Torres and Pace (2005) discussed the attitudes and ideologies that situate white women as being inferior to white males, as was shared by the two female participants. However, the findings revealed that there was no discussion concerning whiteness and feminism in relation to nonwhite females amongst any of the participants, including Iris and Lyra, the two white females. This finding links to Arndt's (2005) and Frankenberg's (1993) discussion on white feminism in which the literature states that white women are racially privileged because of their whiteness. Therefore, critical awareness is absent in how their gender is positioned in society amongst nonwhite females.

In contrast, when Steve spoke about gender and patriarchy, he spoke about the origins of this phenomenon and linked it to Western Europe as historically being the dominant global player which was comprised predominately of white males. This reflects Hatt's (2016) discussion on the construction of a white male through the historical, cultural, political and social factors that are ingrained in society which link whiteness to patriarchy and masculinity. As a result, it ties back to the previous findings of Torres and Pace (2005) regarding white women being subordinate to white males. 
There was a collective understanding of the historical construction of academia. Each participant explained why academia was grounded in Eurocentric ideologies that uplifted whiteness and white supremacy. These findings resonate with Brunsma, Brown and Placier's (2012) discussion regarding academia traditionally being known as a 'white university' or 'white campuses.' All three participants discussed the vast diversity displayed at RU. Each participant shared that diversity is visible amongst staff, students, and within their program, whether through course readings, guest speakers and professors; however, at times topics on whiteness and white privilege are seldomly discussed. These findings contradict the discoveries of Mohamed and Beagan (2019) and Murray and Brooks-Immel's (2019) who contend that academia legitimatizes only certain types of knowledge through research, journal articles and curriculum.

Equally important, Iris shared that non-white students are validated more so than white students. Although Iris' finding contradicts Puchner and Roseboro's (2011) discussion concerning white student voices dominating in classrooms, the evident power relations between white and non-white students in classrooms cannot be ignored. Power is behavioural and everyone has the power to mobilize, exercise and influence a desired direction or accomplish an end. However, white individuals inherently possess power that is associated with whiteness. I relate back to Frankenberg's (1993) definition of whiteness, in which the author states whiteness has three dimensions, first it has a structural advantage, second it's how white people look at themselves and others' and third it's a cultural practice (p.1). Therefore, power becomes a tool used by whiteness in which the dominant group employs to "exclude certain people from exercising their rights as equal members of society" (James, Este, Thomas-Bernard, Benjamin, Lloyd \& Turner, 2010, p. 65). In order to disrupt power relations one needs to "accept their responsibility for others' oppression and their own privilege” (Parada, Barnoff, Moffatt, \& 
Homan, 2011, p.107) Although, not to diminish Iris's statement where she shared that non-white voices are heard more so than whites, it is important to note that the voices of racialized and marginalized students have long been excluded from discussions and the time is now for white students to listen as an ally and exercise their power "with" and not "over".

Additionally, RU's 2019-2020 Board Members consist of 24 members; these findings are accessible to the public. Eight of those 24 members are visibly white males, and four are visibly white females, the other half of members visibly identify as non-white. These findings contradict Murray and Brooks-Immel's (2019) discussion regarding post-secondary institutions preserving the hierarchical structures and inequalities amongst its staff. However, as Tanner (2018), Marom (2017) and Hikido and Murray (2016) clarify, tertiary institutions use multiculturalism as a tool to promote diversity; however, the 'language of diversity' does not reflect multiculturalism instead it preserves discourses of colonialism, racism and witnesses. Whether that is unconsciously taking part at RU, we may never know, unless individuals speak out about it.

Terms such as being "watched," "filtering," "double standard," "disregarded," and "invalidated" were commonly discussed by Lyra, Iris and Steve, when they talked about feelings of being excluded, isolated or silenced due to their whiteness. As I reflect on my feelings of whiteness, I acknowledge that I have felt in the past the need to regulate my own actions, so to not appear to or be challenged for using my white female privilege. These compelling statements and revelations of the participants and myself align with the findings of Matias and Newlove (2017) discussion on whiteness. The authors assert that whiteness is conceived as the "normative" and appears "natural". Consequently, societies function under these illusions of "naturality". However, once whiteness becomes challenged do these invisible shields unravel themselves? Thus, these feelings, statements and observations of the participants and myself may 
occur because the "natural" displacement of whiteness is being exposed and challenged, therefore, making it feel "un-natural" or "un-normal" to white individuals.

Each participant acknowledged that oppression, racism, and discrimination do exist; however, they explained that the constant reinforcement and media coverage does not tackle the issue or find solutions. Instead, there is an overwhelming feeling of propaganda of whiteness at RU. Steve shared that he has become immune to the ways in which whiteness is demonstrated as he believes it is 'blown out of proportion". Iris shared that it can be a "bit eye-rolling" knowing that RU repeatedly attempts to engage students around the issue of whiteness. While Lyra shared at times, its "overplayed" as we are all going through a tough time. This reflects the core findings of whiteness being challenged once un-masked, as discussed by Matias and Newlove (2017). Additionally, I would argue that these statements align with Frankenberg's (1993) colonial discourse of the white/Western self, in contrast to the marked racial Other (p.17). The author explains that the white/Western self has historically remained "unexamined" and "unmarked" therefore, when challenged it becomes uncomfortable to the white/Western self-individual (p.17). Conversely, there is a gap in the literature that does not discuss whether post-secondary institutions are challenging whiteness and if they are, how effective has it been.

The participants Steve and Lyra shared that they have unconsciously perpetrated whiteness through thought or action, such as making stereotypical jokes. Steve and Lyra shared that these jokes were innocent and not meant to harm anyone. However, they explained that white people had been the center of laughs too. Iris shared that she had a "thought," which initially seemed harmless which might have perpetrated whiteness. Not until the realization of why she had this "thought" did the participant change her perspective. Reflecting on my actions of whiteness, I acknowledge that I too unconsciously have perpetrated whiteness, by making 
assumptions and justifying it because it seemed "natural." As to why I felt the need to partake in these actions, I believe links to Matias and Newlove's (2017) discussion on white supremacy where whites feel a sense of superiority, which is manifested through forms of oppression and discrimination over marginalized groups.

There were feelings of discomfort whenever discussions of whiteness, oppression and discrimination occurred as reflected by the participants' attitudes. Lyra spoke of wanting to intervene but knew nothing would come out of it, whereas Iris spoke of intervening because it was right to do so and not due to one's identity, such as race or gender. In contrast, Steve disclosed that he believed he would not intervene. There is a gap in the literature as it does not discuss ways whites intervene against whiteness. However, I ponder whether or not to intervene is to keep the "natural" order of whiteness intact. As I reflect on my own responsibility for challenging whiteness, I acknowledge that there were times when I had intervened when discussions of whiteness, oppression and discrimination occurred. Most of these conversations occurred outside of my own program or on campus, where I have had to re-educate peers about the colonial history that has affected many marginalized communities globally.

Lyra, Iris and Steve all acknowledged that whiteness refers to a structural advantage as per Frankenberg's (1993) definition on whiteness. However, each participant affirms that whiteness on a micro-level would be very difficult to challenge and change as there are individuals who only know one narrative. Iris explains that the cause of the challenge and the existence of whiteness is due to the fact that the majority of individuals are "misinformed" or "uneducated" on whiteness. However, I argue that being "misinformed" and "uneducated" on whiteness is a privilege in itself and an excuse that reflects Matias, Viesca, Garrison-Wade, 
Tandon, \& Galindo's (2014) argument regarding the refusal to acknowledge whiteness which essentially maintains a racist system at the expense of marginalized and racialized groups. Although these interviews were conducted via phone, it is essential to note that the interviewer and participants have never physically seen each other. Therefore, it was interesting to find how comfortable and forthcoming the participants were during the interview. Although some of the questions may have been invasive, the participants provided their honest opinion on the matter. Whether the findings would have been different had we conducted in person interviews is something to consider. 


\section{CHAPTER 7: IMPLICATIONS}

In this study, I have sought the narratives of three RU students on their experiences and understanding of whiteness and how they have either perpetrated or fought against systematic oppression, racism, and marginalization within their academic institution. In this chapter, I will discuss how social work is implicated in this study.

The results indicate that whiteness is not easily defined, as was shown by the three fulltime RU white student participants. Instead, whiteness correlates to individual social location and lived experiences. The data implies that the specific programs that these three participants are enrolled in are moving away from Eurocentric ideologies by incorporating diverse perspectives into their curriculum and by employing younger professors and more racialized faculty. However, the results of the participants suggest that there is still a white male dominance in the academy and white males are held superior to other voices. The findings indicate that whiteness is perpetrated unconsciously through thought or action and in the form of joke making. The analysis suggests that there are feelings of discomfort when speaking out against whiteness, oppression, and discrimination.

In line with the hypothesis by Matias and Newlove (2007) that discuss whiteness as something that is perceived to be "natural," therefore, challenging whiteness is seen as "unnatural," the data revealed patterns that correlated with this theory. Thus, to move towards decolonization and challenging whiteness, emphasis needs to be on critical reflexivity. Critical reflexivity goes deeper than looking within one's privileges. It entails the individual to sit in their discomfort and to be critical of their intersectionality within the spaces they occupy. There is also an emphasis on examining your own biases, values, and assumptions. If not, the shield of whiteness becomes very comfortable for those who do not need to challenge it. 
The results of the current study build on existing knowledge around patriarchy and whiteness. Specifically, white males dominating over white females, as was discussed by Torres and Pace (2005). This finding suggests that even though we live in a diverse, multicultural society, women continue to be subordinate to males. This is important to social work as it is a predominantly female profession; however, those who occupy positions of power within social work institutions and agencies remain male-dominated. Additionally, this research brought new insight into how white males and white females identify whiteness and how they see themselves implicated within. Through this revelation, this research may give insight into how those in positions of power, whether they identify as male or female or as non-binary, define whiteness and whether their policies align with their interpretation.

Moreover, the research provided new insight into feelings about whiteness amongst three white students and whether they felt academia was effectively tackling issues on whiteness, racism, and oppression. This study can help inform academia on ways whiteness is experienced, defined and demonstrated amongst white students as there is a gap within the literature. This study may possibly support the advancement of future policies that may aid post-secondary institutions to decolonize their curriculums and help facilitate discussions on whiteness in programs other than social work. Moreover, this study could potentially assist in incorporating critical whiteness studies and critical pedagogy into their curriculums.

While previous research focused on academia not challenging whiteness by ignoring the structural and institutional level of racism and colonialism (Marom, 2017, p.165), the data suggests that diverse perspectives are, in fact, incorporated in programs other than social work. This is important to consider, as it indicated that post-secondary institutions are making an effort to move away from Eurocentric perspectives. Therefore, this study may aid broader future 
research into post-secondary institutions nationally and how their students are experiencing and understanding whiteness in their institutions. By conducting more comprehensive research into this topic, it may create an educational policy that incorporates these discussions in all programs. As well, this study can also provide insight into what other post-secondary institutions are doing and what they are not doing.

These results should be taken into account when considering the implication of social work. Social workers work in various settings and amongst multi-disciplinary teams with individuals from diverse educational backgrounds and experiences. Therefore, social workers are often very cognizant of their social location in various settings that they occupy as whiteness, privilege and oppression are components of our epistemology and practices. Therefore, whiteness can be very visible to and understood by social workers but this may not necessarily be the case with others who are from different professional training and backgrounds. This study can inform social workers that whiteness discussions may not be as clear amongst graduates from post-secondary institutions as assumed, as was evident amongst the findings of the three participants of the study who came from three different disciplines of study. Therefore, this study can alert social workers, who are involved with multi-disciplinary teams, to the fact that colleagues may not have had the benefit of being taught about whiteness while being trained in their particular field of expertise. In this way, social workers may often have to play an educational role whereby they share their knowledge of whiteness with multi-disciplinary team members. By utilizing critical whiteness pedagogy in these roles, social workers will be better equipped in addressing whiteness to colleagues by providing a critical examination and engagement in the development of whiteness. 
However, it is crucial to take into consideration the limitations of this research study. This research study utilized a narrative approach to inquiry, which only works best with a small number of participants (Creswell, 2013, p.70). Therefore, this research study is based on the stories and lived experiences of three RU full-time white students. Due to the limited sample size, the findings cannot be generalized beyond these participants. Additionally, due to the interviews for this research being conducted via telephone, there was a limitation in forming strong connections with the participants, which could have affected the overall findings and analysis of this research. 


\section{CHAPTER 8: CONCLUSION}

This research aimed to utilized critical white studies and critical white pedagogy to analyze the experiences and understanding of whiteness on the part of three full-time RU white students and how they have either perpetrated or fought against systematic oppression, racism, and marginalization within their academic institution. The initial data was collected by utilizing a narrative approach to inquiry which involved interviewing three RU full-time students. All three participants were interviewed via telephone and using the same interview questionnaire. The study sought to answer three research questions: 1) How do white students attending Ryerson define whiteness? 2) How do white students attending Ryerson understand whiteness in academia? and 3). How have white students attending Ryerson perpetrated or fought against whiteness within their institution?

The data drew on five key themes, 1 . Being white... what does that mean, 2. Patriarchy, 3. What About Us? 4. Exposure to Whiteness, and 5. Moving Forward. The results indicate that whiteness is not easily defined, as was shown by the three full-time RU white student participants. Instead, whiteness correlates to individual social location and lived experiences. Moreover, the results suggest that the participants believe that there is still a white male dominance power amongst academia in which is held superior to other voices. The findings indicate that whiteness is perpetrated unconsciously through thought or action and is in the form of joke making. The analysis suggests that there are feelings of discomfort when speaking out against whiteness, oppression, and discrimination

\section{Recommendations}

Future research is needed to establish white students' interpretation of whiteness in academia and how they see themselves being implicated in it. Furthermore, future studies should 
take into account any current or past actions or policies academia is implementing or has implemented to tackle whiteness in their institutions. Lastly, further research is needed to explore whether gender is a significant attribute in how white students understand, experience, perpetrate or contest whiteness in academia.

\section{Final thoughts}

We are all implicated in whiteness as it has become so infused in our society that it goes unnoticed unless you are from a marginalized or racialized group. We need to do better to disrupt whiteness and challenge those norms. It is a process and a difficult one, but as history has shown us, we have made the impossible possible. It is time for white people to stop and accept their white privileges and challenge them. It is time that our leaders, our educational systems, criminal justice systems, health care systems, policy makers and anyone in power begin to reflect the faces of all Canadians and not the dominant one. The recent events that are surrounding George Floyd's death have tragically unified people globally to put an end to systematic racism, and whiteness. I, myself attended the BlackLivesMatter protest in downtown Toronto right beside Ryerson University. I attended because I stand in solidarity with BlackLivesMatter, as well, I hold myself accountable to the lives that are lost because of systematic racism. The time is now for action, including myself. This research study is my call to action, my decolonization journey to critique my whiteness and examine how I have perpetrated whiteness. In closing, I wish to leave you, especially those who are white individuals, with a quote:

"I've learned that when it comes to race, there's no such thing as neutral: either I'm intentionally and strategically working against it, or I'm aiding and abetting the system." -Debby Irving 


\section{APPENDIX A}

\section{Ryerson University \\ Department of Social Work RESEARCH PARTICIPANTS NEEDED}

\section{Disrupting Whiteness within Academia: Examining the Experiences and Understanding of Whiteness among white students attending Ryerson University}

Are You: Currently enrolled in a part-time or full-time program other than social work at Ryerson University and identify as a white English speaking individual.

If you answered yes to the above noted questions you may volunteer in this study. The study aims to capture the narratives of a maximum 3 Ryerson University's white students and explore their understanding of their white privilege and how they have either perpetrated or fought against systematic oppression within academic institutions.

As a participant in this study, you would be asked to: participate in an telephone interview where you will be asked a series of questions regarding your understanding of whiteness in academia.

Your participation would involve 1-1.5hour individual telephone interview In appreciation of your time, you will receive \$10 Tim Horton's digital gift card.

If you are interested in participating in this study, or would like more information, please contact:

\section{Danuta Gawron, MSW Student \\ School of Social Work, Ryerson University \\ Email: dgawron@ryerson.ca}

This study has been approved by the Ryerson Research Ethics Board (REB: 2019-470) and is being conducted by a graduate student as a requirement for program completion.

Research supervisor Gordon Pon can be reached at g2pon@ryerson.ca or by telephone at 416-9795000 ext. 4786. 


\section{APPENDIX B}

\section{Facebook Recruitment Notice/Posting Script}

Hello all, I hope you are all safe amidst this unprecedented time that we are living,

My name is Danuta Gawron. I am a student at Ryerson University in the School of Social Work Department. I am conducting a research to fulfill my Master of Social Work degree at Ryerson University School of Social Work, titled "Disrupting Whiteness within Academia: Examining the Experiences and Understanding of Whiteness among White Students attending Ryerson University". I am seeking 3 current part-time or full-time students enrolled in a program other than Social Work at Ryerson University who identify as white for my research study.

Your participation will involve 1.1.5hour telephone interview which will be audio-recorded. Your name will not appear in the research as it will be anonymous and replaced with alias. In appreciation of your time, you will receive \$10 Tim Horton's digital gift card.

The research is unfunded and has been reviewed and approved by the Ryerson University Research Ethics Board (REB 2019-470).

If you are interested or have questions about participating, please only reply to this post by directly sending me a personal message to protect confidentiality.

Thank you 


\section{APPENDIX C}

\section{Interview Guide}

\section{DISRUPTING WHITENESS WITHIN ACADEMIA: EXAMINING THE EXPERIENCES AND UNDERSTANDING OF WHITENESS AMONG WHITE STUDENTS ATTENDING RYERSON UNIVERSITY}

\section{Introduction:}

Thank you for agreeing to be part of this study. Before we begin, do you have any questions about the consent form?

This interview will take approximately 1 to 1.5 hours. I want to assure you that everything you say here is confidential, and all identifying information will be removed from your transcript and a pseudonym (unless you have chosen to use your real name for the study) will be used if you are quoted.

During the interview, you may ask to stop recording or take a break at any time. You can also terminate the interview at any point if you feel any discomfort or you decide to change your mind about being part of this research study. Do you have any questions before we begin?

\section{Central Research Question:}

What is your experience and understanding of whiteness at Ryerson University?

\section{Opening Questions:}

$\checkmark$ Can you tell me a little about your educational background?

$\diamond$ What program are you currently enrolled in at Ryerson University? Is it part-time or fulltime? How long is your program?

$\diamond \quad$ What influenced your career path?

$\diamond \quad$ Why did you enrol in this program?

$\diamond \quad$ Are you affiliated with any Ryerson University clubs?

\section{Context Questions:}

\section{Ryerson University:}

$\diamond$ Do you feel diversity at Ryerson University is reflected of Toronto? If not, why?

$\diamond$ Do you believe diversity reflects amongst Ryerson University staff and students? If not, why? If so, how has it been visible?

\section{Program:}

$\diamond$ What has been your experience with diversity within your classrooms at Ryerson University thus far?

$\diamond \quad$ How you do feel your program has incorporated diverse voices? (Whether it be through readings, presentation, or guest speakers).

$\diamond \quad$ Are there discussions about whiteness in any of your classes? If so, to what context and if not, why do you think that is? 
Before we begin, I will be asking you some personal questions. I want to remind you that you may skip any question. If you do not wish to answer the question, you may just say "pass" and I will totally respect your wishes. May I proceed to ask the next question?

\section{Individual:}

$\diamond$ What does privilege mean to you? Who has it and who does not?

$\diamond \quad$ What does whiteness mean to you?

$\diamond \quad$ Do you feel that you have any advantages because you are white? If so, what?

$\diamond$ When you think of equality what does that mean to you?

$\checkmark$ How do you feel when others speak about oppression, racism, and discrimination?

$\diamond$ In what ways do you feel oppressed?

$\checkmark$ How do you understand whiteness in academia?

$\diamond \quad$ How do you see whiteness demonstrated as Ryerson University?

$\checkmark$ Have you witnessed or experienced a situation where white privilege was experienced? What level was it on (e.g. amongst professors; amongst students; amongst professors and students)? Was it gender specific?

$\diamond$ In those situations did you feel as though you should have intervened or not?

$\diamond \quad$ Have there been situations where you have unconsciously taken part in perpetrating whiteness?

$\diamond$ Have there been situations where you have spoken out against whiteness? If so, when? If not, why not?

\section{Concluding Remarks}

Thank you for sharing your time and experiences with me. Is there anything else you would like to share with me? Do you have any questions? 


\section{Ryerson
University}

\section{Ryerson University Consent Agreement}

You are being invited to participate in a research study. Please read this consent form so that you understand what your participation will involve. Before you consent to participate, please ask any questions to be sure you understand what your participation will involve.

\section{DISRUPTING WHITENESS WITHIN ACADEMIA: EXAMINING THE EXPERIENCES AND UNDERSTANDING OF WHITENESS AMONG WHITE STUDENTS ATTENDING RYERSON UNIVERSITY} INVESTIGATORS:

This research study is being conducted by Danuta Gawron, who is a graduate student in the Master of Social Work program at Ryerson. The research is being supervised by Gordon Pon, an Associate Professor at Ryerson University's School of Social Work

If you have any questions or concerns about the research, please feel free to contact Danuta Gawron via email at dgawron@ ryerson.ca.

\section{PURPOSE OF THE STUDY:}

The purpose of the study is to capture the narratives of Ryerson University's White students and explore their understanding of their white privilege and how they have either perpetrated or fought against systematic oppression within academia.

The number of participants for this study is no more than 3 .

Eligibility to participate in this research is current part-time or full-time students enrolled in a program other than Social Work at Ryerson University who identify as white. The research study will be conducted in English. Participants must be able to speak and understand English (either English is their first or additional language).

The completion of this research is to meet the Major Research Paper obligation of my Master of Social Work degree.

\section{WHAT PARTICIPATION MEANS:}

If you volunteer to participate in this study, you will be asked to do the following things: 
- Participate in a 1-1.5hour audio-recorded telephone interview where you will be asked a series of questions regarding your understanding of whiteness. An example interview question is "What is your understanding of whiteness?"

- Phone interviews will be conducted in private quiet room.

- Once your audio-recordings from your telephone interview have been transcribed, a copy will be emailed to you for you to review and/or edit if you choose. You will be given 3 days to edit your transcriptions. You will then need to either forward your edited telephone audio-recorded transcript back to the principal investigator or send an email confirming your approval of the original telephone audio-recorded transcript.

- Participants will review a copy of the final paper delivered by the method of their choice (e.g. in person, mail, or email).

\section{POTENTIAL BENEFITS:}

The possible benefits of participating in this research study will include a gained perspective on whiteness and may make some contributions toward addressing any challenges/needs/concerns around whiteness at Ryerson University.

I cannot guarantee, however, that you will receive any benefits from participating in this study.

\section{WHAT ARE THE POTENTIAL RISKS TO YOU AS A PARTICIPANT:}

Although this research study has very low potential risks, due to the personal nature of the questions asked, a participant may reflect on unpleasant memory or experience feelings of discomfort, embarrassment or exposure while responding to a questionnaire. Participants may skip answering a question or stop participation, either temporarily or permanently when feelings of discomfort occur.

As well, there may be a risk to participants partaking in telephone interviews. Although, the risk is low, there is a possibility that participants may be heard during their telephone interview depending where they are when agreeing to partake in the telephone interview.

Additionally, given that this research study pertains to Ryerson University students, a potential group risk may be involved. Participants may risk being identified as a group of individual(s) in a specific program. This type of group risk is however minimal and little or no harm will come to group members.

A list of community recourse will be given if asked for personal support.

\section{CONFIDENTIALITY:}

Your participation in this research study will be kept confidential to the extent permitted by law. If you disclose any information or evidence regarding harm to self, and/or to others confidentiality would be broken. To maintain confidentiality researchers will use pseudonyms (fake names). 
All data will only ever be kept and accessible by the principal investigator, Danuta Gawron and will not be shared with other parties. Signed consent forms will be stored in a secured locked cabinet at the principal investigator's home from the time of the interview until August 2020 after the final submission of the research study.

The telephone interview will be audio-recorded and stored on the principal investigator's password-protected iPhone. As well, transcriptions will be stored under a password-protected file on the principal investigator's password-protected Mac laptop. Additionally, participants will have the option to have their telephone audio-recorded transcript emailed to them for review and/or edit only once telephone audio-recordings have been transcribed. If you choose to review and/or edit your telephone audio-recorded transcript you will have 3 days to do so. You will then need to either forward your edited telephone audio-recorded transcript back to the principal investigator or send an email confirming your approval of the original telephone audio-recorded transcript. If 3 days have past and the principal investigator has not received an email with an edited version of the telephone audio-recorded transcript or your approval, the original transcript will be used for the research. Additionally, participants will have the option to review the draft of the paper before submission of the MRP to the School of Graduate Studies. Participants will have the option to email me regarding suggested revisions to the analyses that pertain to their interview. We will engage in discussion in determining a collaborative way to incorporate any revisions into the final draft. However, also this process prioritizes dialogue it does not necessarily mean that participant's revisions will be accepted.

The purpose of member checking is to engage in collaborative meaning-making with the participants by obtaining their feedback on my analyses. This process is dialogic and entails a process of discussion of any concerns, questions or alternative analyses that the participants may have. For example, the participant may email me some suggested revisions to the analyses that pertain to their interview. I will engage in discussions with them to determine a collaborative way to incorporate their revisions into my paper. This process prioritizes dialogue and does not necessarily mean that I will accept all of their revisions. Overall, the member checking process aims to increase the rigor of qualitative research by ensuring that I have not misunderstood or misrepresented what my participants shared with me.

In returning the paper to participants I will advise them that they have 5 days to get back to me with any questions or suggested revisions. I will note that after 5 days if I have not heard from them, then I will take it to mean that they are okay with the draft paper.

Telephone audio-recordings, transcriptions and consent forms will only remain on the principal investigator's password-protected Mac laptop and iPhone and will be deleted after the final submission of the Major Research Paper to Ryerson University. The anticipated submission of the final paper is August 2020.

Data will be disseminated in the form of a Major Research Paper, which is part of the requirements of completing the Master of Social Work program at Ryerson University. The final paper will be submitted to the School of Social Work and stored at Ryerson University, which could be accessed by Ryerson students. This research may also be used for publication in a peer- 
reviewed journal. In the event that the research is made public, no personally identifiable information will be shared.

\section{INCENTIVES FOR PARTICIPATION:}

Participants will be offered a \$10 Tim Horton's digital gift card as an incentive for participating in this research. Participants have the right to withdraw voluntarily from participation at any time. Additionally, participants who stop participating at any time will still be given the incentive of a \$10 Tim Horton's digital gift card.

\section{COSTS TO PARTICIPATION:}

There are no costs to participation in the research study.

\section{COMPENSATION FOR INJURY:}

By agreeing to participate in this research, you are not giving up or waiving any legal right in the event that you are harmed during the research.

\section{VOLUNTARY PARTICIPATION AND WITHDRAWAL:}

Participation in this study is completely voluntary. You can choose whether to be in this study or not. If any question makes you uncomfortable, you can skip that question. You may stop participating at any time and you will still be given the incentives and reimbursements described above. If you choose to stop participating, you may also choose to not have your data included in the study. However, after June 2020, the data will be not removed because it will have been integrated into the overall analysis. Your choice of whether or not to participate will not influence your future relations with Ryerson University or the investigator Danuta Gawron involved in the research.

\section{QUESTIONS ABOUT THE STUDY:}

If you have any questions about the research now, please ask. If you have questions later about the research, you may contact Danuta Gawron via email at dgawron@ryerson.ca or the research supervisor Gordon Pan at g2pon@ ryerson.ca or by telephone at 416-979-5000 ext. 4786.

This study has been reviewed by the Ryerson University Research Ethics Board. If you have questions regarding your rights as a participant in this study please contact:

\section{Research Ethics Board}

c/o Office of the Vice President, Research and Innovation

Ryerson University

350 Victoria Street

Toronto, ON M5B 2K3

416-979-5042

rebchair@ryerson.ca 


\section{DISRUPTING WHITENESS WITHIN ACADEMIA: EXAMINING THE EXPERIENCES AND UNDERSTANDING OF WHITENESS AMONG WHITE STUDENTS ATTENDING RYERSON UNIVERSITY}

\section{CONFIRMATION OF AGREEMENT:}

Your signature below indicates that you have read the information in this agreement and have had a chance to ask any questions you have about the study. Your signature also indicates that you agree to participate in the study and have been told that you can change your mind and withdraw your consent to participate at any time. You have been given a copy of this agreement. You have been told that by signing this consent agreement you are not giving up any of your legal rights.

Name of Participant (please print)

Signature of Participant

Date

I agree to be audio-recorded during my telephone interview for the purposes of this study. I understand how these recordings will be stored and destroyed.

Signature of Participant

Date

I agree to have by telephone audio-recorded transcript emailed to me for review and/or edit. I understand that if I choose to review and edit my telephone audio-recorded transcript I have 3 days to do so and am required to either email the primary investigator with my edited version or email approval of the original. I understand that if I have not emailed the principal investigator after the 3 days of receiving the transcript, the original transcript will be used for the research.

Please circle one of the following:

I wish to review and/or my telephone audio-recorded transcript $\quad$ YES

I do not wish to review and/or my telephone audio-recorded transcript NO

Signature of Participant

Date

APPENDIX E 


\section{Ryerson University}

Research

\section{To: DANUTA GAWRON}

\section{Social Work}

Re: REB 2019-470: Disrupting whiteness within academia: Examining Ryerson

University's white students experiences and understanding of whiteness.

Date: February 21, 2020

\section{Dear DANUTA GAWRON,}

The review of your protocol REB File REB 2019-470 is now complete. The project has been approved for a one year period. Please note that before proceeding with your project, compliance with other required University approvals/certifications, institutional requirements, or governmental authorizations may be required.

This approval may be extended after one year upon request. Please be advised that if the project is not renewed, approval will expire and no more research involving humans may take place. If this is a funded project, access to research funds may also be affected.

Please note that REB approval policies require that you adhere strictly to the protocol as last reviewed by the REB and that any modifications must be approved by the Board before they can be implemented. Adverse or unexpected events must be reported to the REB as soon as possible with an indication from the Principal Investigator as to how, in the view of the Principal Investigator, these events affect the continuation of the protocol.

Finally, if research subjects are in the care of a health facility, at a school, or other institution or community organization, it is the responsibility of the Principal Investigator to ensure that the ethical guidelines and approvals of those facilities or institutions are obtained and filed with the REB prior to the initiation of any research.

Please quote your REB file number (REB 2019-470) on future correspondence. Congratulations and best of luck in conducting you research.

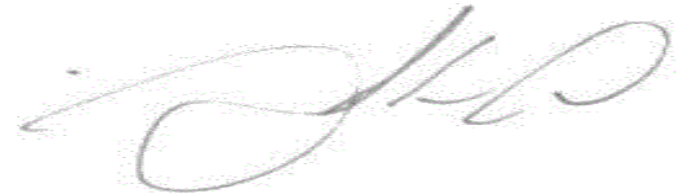

Dr. Asher Alkoby, LL.B., LL.M., S.J.D.

Chair, Ryerson University Research Ethics Board

(416)979-5000 ext. 2491

aalkoby@ ryerson.ca

rebchair@ryerson.ca

http://www.ryerson.ca/research 
The Following protocol attachments have been reviewed and approved.

- $\quad$ Appendix D Consent Form Feb 8.docx (submitted on: 08

- Feb 2020) Appendix C In Person Script.docx (submitted on:

- $\quad 08$ Feb 2020) tcps2-eptc2-certificate.pdf (submitted on: 08 Feb 2020)

- $\quad$ Appendix A Reference .docx (submitted on: 08 Feb 2020)

- $\quad$ Comments to Chair Feb 8.docx (submitted on:08 Feb 2020)

- $\quad$ Appendix B Flyer Feb 8.docx (submitted on: 08 Feb 2020)

- $\quad$ Appendix E Email Script Feb 8.docx (submitted on: 08 Feb

- 2020) Appendix F List of resources Feb 8.docx (submitted

- on: 08 Feb 2020) Appendix G-Interview Guide .docx (submitted on: 08 Feb 2020)

If any changes are made to the attached document throughout the course of the research, an amendment MUST be submitted to, and subsequently approved by the REB. 


\section{Endnotes}

Campbell, F. A. K. (2008). Exploring internalized ableism using critical race theory. Disability \& Society, 23(2), 151-162. doi:10.1080/09687590701841190

Shen, W., Mao, X., Hu, X., \& Wong, T. (2016). Seamless visual sharing with color vision deficiencies. ACM Transactions on Graphics (TOG), 35(4), 1-12.

doi: $10.1145 / 2897824.2925878$ 


\section{References}

Ambrosio, J. (2014). Teaching the psychosocial subject: White students and racial privilege. International Journal of Qualitative Studies in Education, 27(10), 1376-1394. doi:10.1080/09518398.2013.840402

Applebaum, B. (2016). Critical whiteness studies. Oxford Research Encyclopedia of Education. Retrieved January 6, 2020, from https://oxfordre.com/education/view/10.1093/acrefore/9780190264093.001.0001/acrefore $-9780190264093-e-5$.

Applebaum, B. (2005). In the name of morality: Moral responsibility, whiteness and social justice education. Journal of Moral Education, 34(3), 277-290. doi:10.1080/03057240500206089

Arndt, S. (2005). Boundless whiteness? feminism and white women in the mirror of African feminist writing. Matatu, 29(1), 157-172. doi:10.1163/18757421-029030011

Baffoe, M., Asimeng-Boahene, L., \& Ogbuagu, B. C. (2014). Their way or no way: "Whiteness" as agent for marginalizing and silencing minority voices in academic research and publication. European Journal of Sustainable Development, 3(1), 13-32. doi:10.14207/ejsd.2014.v3n1p13

Bohonos, J. W. (2019). Including critical whiteness studies in the critical human resource development family: A proposed theoretical framework. Adult Education Quarterly, 69(4), 315-337. doi:10.1177/0741713619858131

Brunsma, D. L., Brown, E. S., \& Placier, P. (2012). Teaching race at historically white colleges and universities: Identifying and dismantling the walls of whiteness. Critical Sociology, 39(5), 717-738. doi:10.1177/0896920512446759 
Charbeneau, J. (2015). White faculty transforming whiteness in the classroom through pedagogical practice. Race, Ethnicity and Education, 18(5), 655-674. doi:10.1080/13613324.2013.831823

Creswell, J.W. (2013). Qualitative inquiry and research design: Choosing among five approaches ( ${ }^{\text {rd }}$ ed.). (pp.69-110). Thousand Oaks, CA: SAGE Publications.

de Freitas, E., \& McAuley, A. (2008). Teaching for diversity by troubling whiteness: Strategies for classrooms in isolated white communities. Race, Ethnicity and Education, 11(4), 429442. doi:10.1080/13613320802479018

Dei, G.S.J.(1996). Critical perspectives in anti-racism. Canadian Review of Sociology and Anthropology, 33(3), 247-267.

Doucet, W.C. (2007). A brief history of Ryerson University. Retrieved December 11, 2019, from https://library.ryerson.ca/asc/archives/ryerson-history/brief-history/

Duhaney, P. (2010). Why is our educational system still guilty of whiteness? Canadian Social Work Review/Revue Canadienne De Service Social, 27(1), 95-111.

Dyer, R. (1997). Coloured white, not coloured. In Dryer, R., White. (pp.41-82).

Faulkner, S. S., \& Faulkner C. A., (2014). Qualitative Research Designs. In Faulkner, S., \& Faulkner C.A., (2nd ed.). Research methods for social workers: A practice-based approach, (pp.85-125). Chicago: Lyceum Books, Linc.

Flintoff, A., \& Dowling, F. (2019). 'I just treat them all the same, really': Teachers, whiteness and (anti) racism in physical education. Sport, Education and Society, 24(2), 121-133. doi:10.1080/13573322.2017.1332583

Foote, N. (2013). Introduction. In Foote, N., The Caribbean history reader (pp.ix-i).

Frankenberg. R. (1993). Introduction: Points of origin, points of departure. In Frankenberg, R., 
The Social Construction of white women, Whiteness race matters (pp.1-22). Minnesota: Regents of the University of Minnesota.

Gillborn, D. (2006). Citizenship education as placebo: 'standards', institutional racism and education policy. Education, Citizenship and Social Justice, 1(1), 83-104. doi:10.1177/1746197906060715

Han, K. T., \& Leonard, J. (2017). Why diversity matters in rural America: Women faculty of color challenging whiteness. The Urban Review, 49(1), 112-139. doi:10.1007/s11256016-0384-7

Hatt, B. (2016). Racializing smartness. Race Ethnicity and Education, 19(6), 1141-1148. doi:10.1080/13613324.2016.1168537

Healy, K. (2014). Modern critical social work from radical to anti-oppressive practice. In Healy, K. (2nd ed.). Social work theories in context: Creating frameworks for practice (pp.183-205). England, Palgrave Macmillan.

Hikido, A., \& Murray, S. B. (2016). Whitened rainbows: How white college students protect whiteness through diversity discourses. Race Ethnicity and Education, 19(2), 389-411. doi:10.1080/13613324.2015.1025736

Howard, P. S. (2018). A laugh for the national project: Contemporary Canadian blackface humour and its constitution through Canadian anti-blackness. Ethnicities, 18(6), 843-868. doi:10.1177/1468796818785936

James, C., Este, D., Thomas-Bernard, W., Benjamin, A., Lloyd, B., \& Turner, T. (2010). The multiple manifestations of racism. In James, C., Este, D., Thomas-Bernard, W., Benjamin, A., Lloyd, B., \& Turner, T. ( $1^{\text {st }}$ ed.). Race and well being, the lives, hopes, and activism of African Canadians (pp.64-88). Halifax: Fernwood. 
Knight, H. (2019). Imagining institutions of man: Constructions of the human in the foundations of Ontario public schooling curriculum. Curriculum Inquiry, 49(1), 90-109. doi:10.1080/03626784.2018.1552071

Leonardo, Z., \& Porter, R. K. (2010). Pedagogy of fear: Toward a Fanonian theory of 'safety' in race dialogue. Race Ethnicity and Education, 13(2), 139-157.

doi:10.1080/13613324.2010.482898

Loop Submission. (2018, Feb 1). Waking Up White - Finding Myself in the Story of Race.

The Loop. Retrieved May 31, 2020 from

http://vashonloop.com/news/community/waking-up-white-finding-myself-in-the-storyof-race/

Marom, L. (2019). Under the cloak of professionalism: Covert racism in teacher education. Race Ethnicity and Education, 22(3), 319-337. doi:10.1080/13613324.2018.1468748

Marom, L. (2017). "We have to be really careful with what we say": Critical discourses across difference in pre-service teacher education. Review of Education, Pedagogy, and Cultural Studies, 39(2), 161-189. doi:10.1080/10714413.2017.1296280

Matias, C. E., \& Mackey, J. (2016). Breakin’ down whiteness in antiracist teaching: Introducing critical whiteness pedagogy. The Urban Review, 48(1), 32-50. doi:10.1007/s11256-0150344-7

Matias, C. E., \& Newlove, P. M. (2017). The illusion of freedom: Tyranny, whiteness, and the state of US society. Equity \& Excellence in Education, 50(3), 316-330. doi:10.1080/10665684.2017.1336951

Matias, C. E., Viesca, K. M., Garrison-Wade, D. F., Tandon, M., \& Galindo, R. (2014). "What is 
critical whiteness doing in our nice field like critical race theory?" Applying CRT and CWS to understand the white imaginations of white teacher candidates. Equity \& Excellence in Education, 47(3), 289-304. doi:10.1080/10665684.2014.933692

Mohamed, T., \& Beagan, B. L. (2019). 'Strange faces' in the academy: Experiences of racialized and indigenous faculty in Canadian universities. Race Ethnicity and Education, 22(3), 338-354. doi:10.1080/13613324.2018.1511532

Murray, S. B., \& Brooks-Immel, D. R. (2019). White moves and counter-moves: The doing and undoing of whiteness in academe. Whiteness and Education, 4(2), 162-179. doi:10.1080/23793406.2019.1655787

Nakamura, M. (2019). Working with faculty of color at a predominantly white institution: Challenging whiteness and model minority stereotypes. New Directions for Teaching and Learning, 158, 49-58. doi:10.1002/t1.20338

Nayak, A. (2007). Critical whiteness studies. Sociology Compass, 1(2), 737-755. Doi: 10.1111/j.1751-9020.2007.00045.x

Nichols, D. (2010). Teaching critical whiteness theory: What college and university teachers need to know. Understanding \& dismantling privilege, 1(1), 1-12. Retrieved January 6, 2019, from https://www.wpcjournal.com/article/view/5421

O'Neill, F. (2013). Making sense of being between languages and cultures: A performance narrative inquiry approach. Language and Intercultural Communication, 13(4), 386-399. doi:10.1080/14708477.2012.758733

Padgett, D.K. (2017). Choosing the right qualitative approach(es). In Padgett, D.K. (3rd ed). Qualitative methods in social work research (pp.31-56). Los Angeles: SAGE Padgett, D.K. (2017). Designing the study and getting started. In Padgett, D.K. (3rd ed). 
Qualitative methods in social work research (pp.57-78). Los Angeles: SAGE

Parada, H., Barnoff, L., Moffatt, K., \& Homan, M. (2011). Power. In H. Parada, L. Barnoff, \& K.M. Homan, Community Change. Making it happen in the real world (Canadian First ed., pp.87-109). Toronto: Nelson.

Phillips, D., \& Pon, G. (2018). Anti-black racism, bio-power, and governmentality: Deconstructing the suffering of black families involved with chid welfare. Journal of Law and Social Policy 28, 81-100. http://digitalcommons.osgoode.yorku.ca/jlsp/vol28/iss 1/5

Pilkington, A. (2013). The interacting dynamics of institutional racism in higher education. Race Ethnicity and Education, 16(2), 225-245. doi:10.1080/13613324.2011.646255

Probst, B. (2015). The eye regards itself: Benefits and challenges of reflexivity in qualitative social work research. Social Work Research, 39(1), 37-48. doi:10.1093/swr/svu028

Pon, G., Gosine, K., \& Phillips, D. (2011). Immediate response: Addressing anti-native and antiblack racism in child welfare. International Journal of Child, Youth and Family Studies, 2(3/4), 385. doi:10.18357/ijcyfs23/420117763

Puchner, L., \& Roseboro, D. L. (2011). Speaking of whiteness: Compromise as a purposeful pedagogical strategy toward white students' learning about race. Teaching in Higher Education, 16(4), 377-387. doi:10.1080/13562517.2010.546528

Ro, C. (2019, Feb 25). 10 Quotes about whiteness. Book Riot. Retrieved December 11, 2019, from https://bookriot.com/2019/02/25/quotes-about-whiteness/

Ryerson University. (n.d.). About. Retrieved December 11, 2019, from https://www.ryerson.ca/about/

Schulz, S., \& Fane, J. (2015). A healthy dose of race? white students' and teachers' unintentional 
brushes with whiteness. Australian Journal of Teacher Education (Online), 40(11), 137154. doi:10.14221/ajte.2015v40n11.8

Shibli, A. (2019). Dismantling systemic racism in Canadian post-secondary institutions: Arab Students' experiences on campus. Canadian Arab Institute. Retrieved February 14, 2020, from http://canadianarabinstitute.org/files/3815/5128/7491/Dismantling_Systemic_Racism_in_ Canadian_Post-Secondary_Institutions-_Arab_Students_Experiences_on_Campus.pdf Statistics Canada. (2017). Census profile, 2016 Census. (98-316-X2016001). [Data set]. Ottawa. Retrieved December 11, 2019, from https://www12.statcan.gc.ca/censusrecensement/2016/dppd/prof/details/page.cfm?Lang=E\&Geo1=POPC\&Code1=0944\&Geo2=PR \&Code2=35\& SearchText=Toronto $\&$ SearchType $=$ Begins $\&$ SearchPR $=01 \& \mathrm{~B} 1=\mathrm{All} \& \mathrm{GeoLevel}=\mathrm{PR} \& \mathrm{Ge}$ oCode $=0944 \&$ TABID $=1 \&$ type $=0$

Tanner, S. J. (2018). My teaching, my whiteness. JCT (Online), 32(3), 79-92.

Todd, N.R., Spanierman, L. B., \& Aber, M. S. (2010). White students reflecting on whiteness: Understanding emotional responses. Journal of Diversity in Higher Education, 3(2), 97110. doi:10.1037/a0019299

Torres, G., \& Pace, K. (2005). Understanding patriarchy as an expression of whiteness: Insights from the Chicana movement. Washington University Journal of Law \& Policy, 18, 129172.

Tuck, E., and Yang, K.W. (2012). Decolonization is not a metaphor. In Decolonization: Indigeneity, Education \& Society, 1(1), 1-40.

Yeung, J. G., Spanierman, L. B., \& Landrum-Brown, J. (2013). Being white in a multicultural 
society: Critical whiteness pedagogy in a dialogue course. Journal of Diversity in Higher Education, 6(1), 17-32. doi:10.1037/a0031632

Yee, J. Y. (2017). Carrying out research on whiteness, white supremacy, and racialization processes in social service agencies. In Parada, H., \& Wehbi, S. Reimagining AntiOppression Social Work Research (pp.61-70). Halifax: Fernwood Press. 